\title{
Genus Microsternus Lewis ( 1887 ) from China, with description of a new genus Neosternus from Asia (Coleoptera, Erotylidae, Dacnini)
}

\author{
Cong-Chao Dai ${ }^{1, \dagger}$, Mei-Jun Zhao ${ }^{2, \dagger}$ \\ I Department of Biology, College of Life and Environmental Sciences, Shanghai Normal University, Shanghai, \\ 200234, P. R. China \\ † http://zoobank.org/F296F7D8-8259-4A69-841C-C2F74F0A54E7 \\ † http://zoobank.org/FBE4FA1F-5BCF-405E-98C1-4F86894643EA \\ Corresponding author: Mei-Jun Zhao (mjzhao@shnu.edu.cn)
}

Academic editor: M. Thomas | Received 5 August 2013 | Accepted 30 September 2013 | Published 4 October 2013

http://zoobank.org/38890FOF-4F06-437B-866E-D057715FCBBC

Citation: Dai C-C, Zhao M-J (2013) Genus Microsternus Lewis (1887) from China, with description of a new genus Neosternus from Asia (Coleoptera, Erotylidae, Dacnini). ZooKeys 340: 79-106. doi: 10.3897/zookeys.340.6044

\begin{abstract}
This work treats species of the genus Microsternus Lewis, 1887 from Asia and North America. A new genus is described: Neosternus (type species Microsternus higonius Lewis, 1887). A new species is described: Microsternus pengzhongi. A new synonym is provided: Microsternus tricolor taiwanicus Nakane (=Microsternus tricolor Lewis). Three species previously placed in Microsternus Lewis, 1887 are transferred to Neosternus resulting in the following three new combinations: Neosternus higonius (Lewis, 1887), Neosternus taiwanus (Chûjô, 1976), and Neosternus hisamatsui (Nakane, 1981).
\end{abstract}

\section{Keywords}

Coleoptera, Erotylidae, Dacnini, Microsternus, Neosternus, identification key, new Genus, new species, new synonym, Asia, China 


\section{Introduction}

\section{General introduction}

The family Erotylidae is composed of fungus feeding beetles which vary greatly in body size and color; many are elaborately patterned. Crotch's (1876) world revision of the Erotylidae was the last study to cover the entire Old World fauna at the species level, but it provided no keys nor illustrations, and only a few short descriptions. In the time between Chûjô and Chûjô 's (1988) catalog of the Old World erotylids and Wegrzynowicz's (2006) catalog of the Palaearctic erotylids, the China erotylid fauna had been studied intermittently, with scattered regional studies, checklists, and species descriptions. Most Chinese erotylid genera have no modern revisions.

\section{Taxonomic arrangement}

Wegrzynowicz (2002) formally synonymized the tribes Megalodacnini and Encaustini. More recent phylogenetic work by Leschen (2003), Robertson et al. (2004), and Leschen and Buckley (2007) were either inconclusive or resulted in different tree topologies that indicate more work is needed to better establish relationships of all tribes before making further taxonomic changes.

Herein, tribal placement of included taxa follows a five-tribe system: Dacnini, Megalodacnini, Encaustini, Erotylini, Tritomini (Lawrence and Newton 1995). China has three genera arranged under tribe the Dacnini: Dacne, Microsternus and Neosternus gen. n.

\section{History}

The first described member of the genus Microsternus Lewis is Megalodacne ulkei Crotch (1873). In studying the Japanese erotylid specimens, Lewis (1883) described Episcapha perforata, but on further study of these group, Lewis (1887a) found three similar Japanese species required a genus to be formed for their reception. Together with Episcapha perforata, Lewis thought these four species were congeneric with American species Megalodacne ulkei and established the genus Microsternus. Lewis (1887b) transferred Episcapha perforata into Microsternus becoming Microsternus perforatus (Lewis, 1883) and described three other species as Microsternus higonius Lewis (1887b), Microsternus crotchi Lewis (1887b) and Microsternus tricolor Lewis (1887b).

Before our study, there were 17 valid species and 1 subspecies placed in the genus $M i$ crosternus Lewis: Microsternus ulkei Crotch (1873), Microsternus perforatus (Lewis, 1883), Microsternus crotchi Lewis (1887b), Microsternus higonius Lewis (1887b), Microsternus tricolor Lewis (1887b), Microsternus cribricollis Gorham (1895), Microsternus puncticollis Heller (1918), Microsternus queenslandicus Heller (1918), Microsternus javanus Deelder 
(1942), Microsternus sumatranus Deelder (1942), Microsternus tokioensis Nakane (1961), Microsternus yamadai Chûjô \& Shibata (1963), Microsternus tricolor taiwanicus Nakane (1966), Microsternus quatei Chûjô (1968), Microsternus bhutanensis Chûjô (1975), Microsternus taiwanus Chûjô (1976), Microsternus hisamatsui Nakane (1982), Microsternus nakanoi Narukawa (2004). Only one species and one subspecies have been reported from China (Taiwan), Microsternus taiwanus and Microsternus tricolor taiwanicus. No record has been reported from the Chinese mainland.

In this work, while examining the specimens of Microsternus from China, we described a new species Microsternus pengzhongi sp. n. from Hainan Prov. and reduce Microsternus tricolor taiwanicus Nakane to a synonym of Microsternus tricolor Lewis. After genitalic dissections and comparisons of head and pronotum structures, we recognized that the genus Microsternus can be divided in two species-groups. Microsternus higonius Lewis (1887b), Microsternus taiwanus Chûjô (1976) and Microsternus hisamatsui Nakane (1982) are not congeneric with the type species of Microsternus Lewis, Microsternus ulkei Crotch (1873). Unlike typical Microsternus, the species, M. higonius, $M$. taiwanus and $M$. hisamatsui do not have the pit posterior to the postmandibular lobes; pronotum has a deep sulcus along each side, which is broadly margined and formed thicken lines in lateral view; male genitalia with flagellum curved, bearing a dorsal, arched, cartilaginous mass on apical quarter, along with prosternum and mesosternum characters not present in other members of Dacnini. Here we describe a new genus Neosternus for these three species.

\section{Characters and terminology}

\section{Male genitalia}

The internal sac of the male genitalia is held invaginated within the median lobe. During copulation, the internal sac is everted; exposing any microstructure and extending the flagellum. The median lobe, internal sac, and flagellum are the true copulatory organs and show the majority of species specific characters. For additional insight into the genitalia of Erotylidae see Skelley (1998) and Skelley and Leschen (2007).

In this work, after dissection of the internal sac, we found the dorsal lobe of $M i$ crosternus has obvious differences that are important characters in species recognition.

\section{Female genitalia}

Female genitalia seemed to vary little from species to species. Structures varied in proportions, but species recognition based on female genitalia was not possible with any degree of confidence. The sclerotized spermatheca showed some variation in shape which could be useful to determine relationships within the genus. See Skelley (1998). 


\section{Material and methods}

In addition to extensive collecting by the authors and their colleagues, Chinese specimens of the tribe Dacnini were borrowed from Wen-xuan Bi's private collections. North America specimens of the genus Microsternus were provided for study from Florida State Collection of Arthropods, USA [Paul E. Skelley]. The photos of type specimens were taken from The Natural History Museum, London, England.

Erotylids were collected in a wide variety of woodland fungi, in crevices under bark or in other retreats by splitting and sifting, and in light traps. For an examination of the male genitalia, the abdominal segments were detached from the body after softening in hot water. The genitalia, together with other dissected parts, were mounted in Euparal (Chroma Gesellschaft Schmidt, Koengen, Germany) on plastic slides. Photos of sexual characters were taken with a FUJIFILM X10 camera attached to an Olympus SZX 16 stereoscope; habitus photos were taken with a Canon macro photo lens MP-E $65 \mathrm{~mm}$ attached to a Canon EOS7D camera.

The specimens treated in this study are deposited in the following public and private collections:

SNUC Department of Biology, Shanghai Normal University, P. R. China

FSCA Florida State Collection of Arthropods, USA [Paul E. Skelley]

NHM The Natural History Museum, London, England

CBWX Collection of Wen-xuan, Bi, Shanghai, China

\section{Taxonomy}

\section{Key to genus of Dacnini from China}

1 Mesosternum exposed; eyes not very coarsely facetted.......... Dacne Latreille

- $\quad$ Prosternal process covering the mesosternum; eyes very coarsely facetted ....2

2 Head with the pit posterior to the postmandibular lobes, pronotum without a deep sulcus along each side and narrowly margined in lateral view

Microsternus Lewis

- $\quad$ Head without the pit posterior to the postmandibular lobes, pronotum with a deep sulcus along each side, which is broadly margined in lateral view .......

Neosternus Dai \& Zhao, gen. n.

Genus Microsternus Lewis, 1887

http://species-id.net/wiki/Microsternus

Figs 1-2, 3-6, 7-8, 9-12, 13-14, 15-21, 22-23, 24-29, 30-33, 40-42, 45-47, 50-52, $59-64,73-74,77-78$

Type species. Megalodacne ulkei Crotch, 1873 

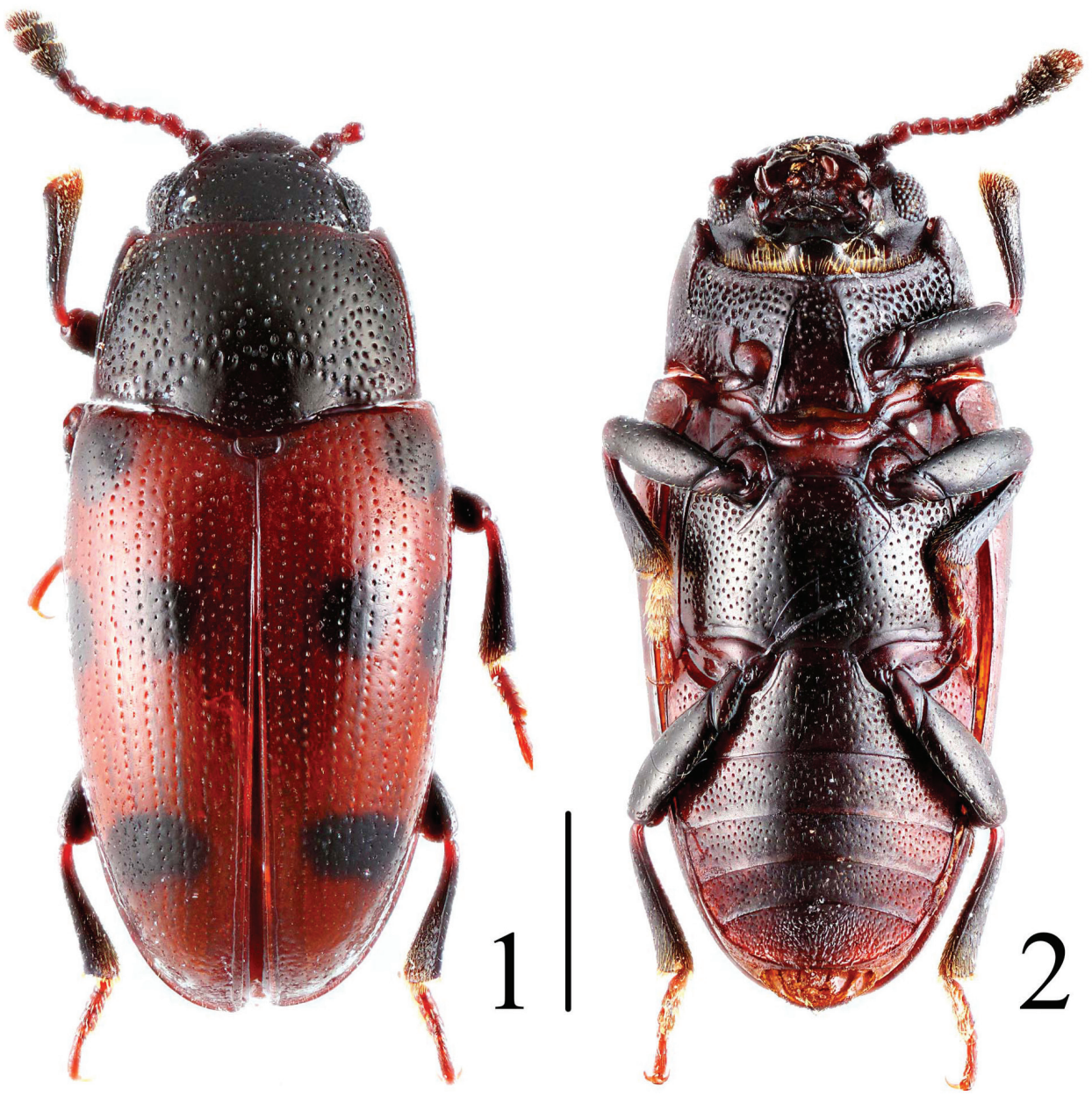

Figures I-2. Habitus of Microsternus ulkei in dorsal and ventral view. Scale $=1 \mathrm{~mm}$.

Description. Body (Figs 1-2, 7-8, 13-14, 22-23, 73-74, 77-78) small, elongate, with legs short and robust, the tarsi cylindrical, 5-jointed, the four basal joints short, nearly equal in size and not at all dilated, the last joint long. Antennae not very long, the latter with a broad 3-jointed club. Eyes coarsely facetted. Head with the pit posterior to the postmandibular lobes (Figs 40-42). Maxillary and labial terminal palpomeres acuminate, sensory area restricted to apex. Pronotum (Figs 45-47) arched, widest at base; narrowed from base to apex, with formed thinned lines in lateral view (Figs 50-52); disk punctured, except the impunctate medio-basal area, which is limited by an arched transverse row of coarse punctures. Prosternum with median area including its process elevated in an elongate triangular plane, which is distinctly bordered by a ridge on both sides and shortly rounded-subtruncate in front. Mesosternum almost concealed by prosternal process. Metasternum with a pair of mesocoxal lines 


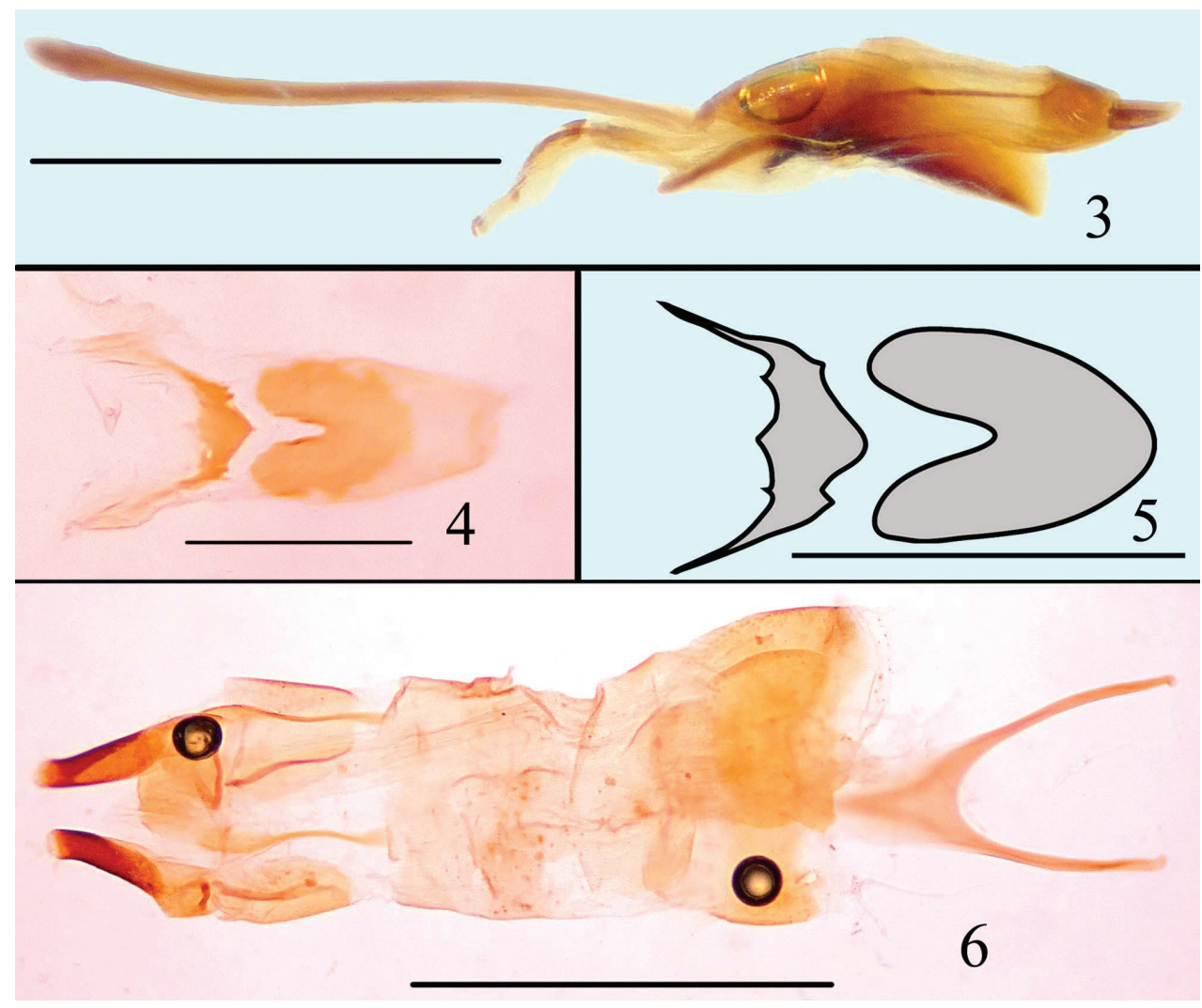

Figures 3-6. Male genitalia of Microsternus ulkei in lateral view 3 Dorsal lobe of Microsternus ulkei in dorsal view 4-5 Female genitalia of Microsternus ulkei in dorsal view 6. Scale $=1 \mathrm{~mm}(\mathbf{3}, \mathbf{6})$, Scale $=0.2 \mathrm{~mm}(\mathbf{4}, \mathbf{5})$.

strongly divergent posteriorly. Abdomen without metacoxal lines on basal visible sternite. Elytra convex.

Distribution. Microsternus is widespread in Asia, with one species in Australia and one species in America.

Diagnosis. Defining characters for Microsternus are body elongate, head with the pit posterior to the postmandibular lobes, pronotum without a deep sulcus along each side and narrowed margin in lateral view, mesosternum almost concealed by prosternal process, male genitalia with flagellum (Figs 59-64) bearing a straight mass on apical quarter.

\section{Key to Chinese species of genus Microsternus}

1 Body black to reddish-brown, each elytra black with two narrow orange

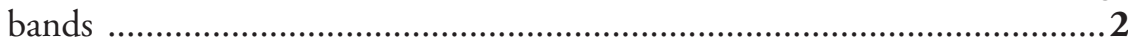

- $\quad$ Body red, elytra with orange and black spots or bands (Figs 22-23) 

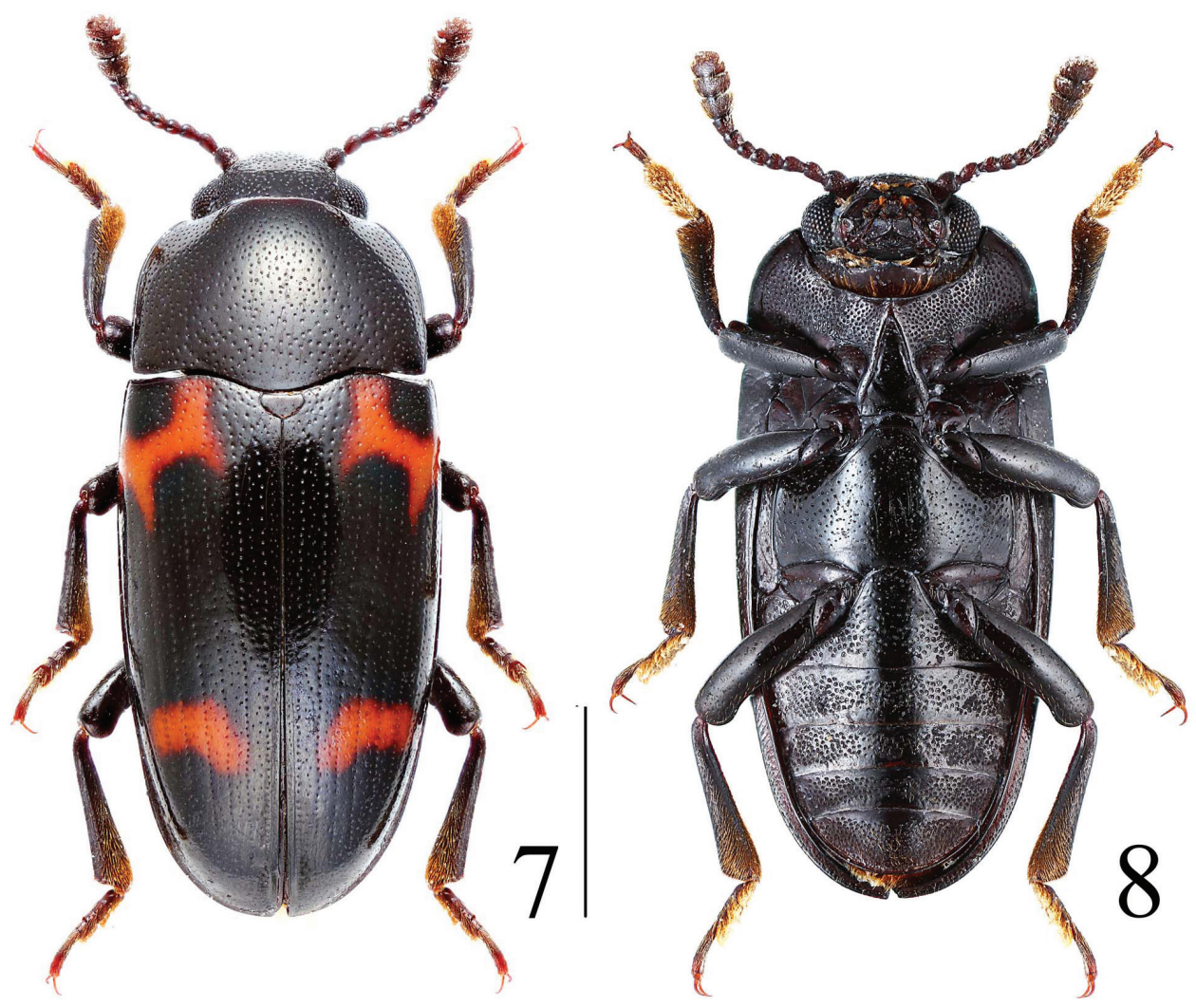

Figures 7-8. Habitus of Microsternus pengzhongi in dorsal and ventral view. Scale $=2 \mathrm{~mm}$.

2 Body shining, punctation of pronotum fine and sparse (Figs 7-8)

Microsternus pengzhongi Dai \& Zhao, sp. n.

- $\quad$ Body not shining, punctation of pronotum coarse and close (Figs 13-14).... Microsternus perforatus (Lewis)

Microsternus pengzhongi Dai \& Zhao, sp. n.

http://zoobank.org/87B144AA-4704-4A78-8A8E-0ACABC75B973

http://species-id.net/wiki/Microsternus_pengzhongi

Figs 7-8, 9-12

Material examined. Holotype: CHINA: Hainan Prov.: $\widehat{\jmath}$, Jianfengling N.R., Mingfenggu Valley, 1844'N, 10850'E, alt. 950 m, 30.IV.2012, Peng \& Dai leg. (SNUC).

Description. Body (Fig. 7, 8) elongate, length: $7.5 \mathrm{~mm}$; width: $3.2 \mathrm{~mm}$. Body black, shining. Each elytron with two narrow orange bands.

Head width between eyes $=4$ times eye diameter in dorsal view; punctation fine, spare, separated by two to four puncture diameters; epistome truncate, lacking marginal line on 


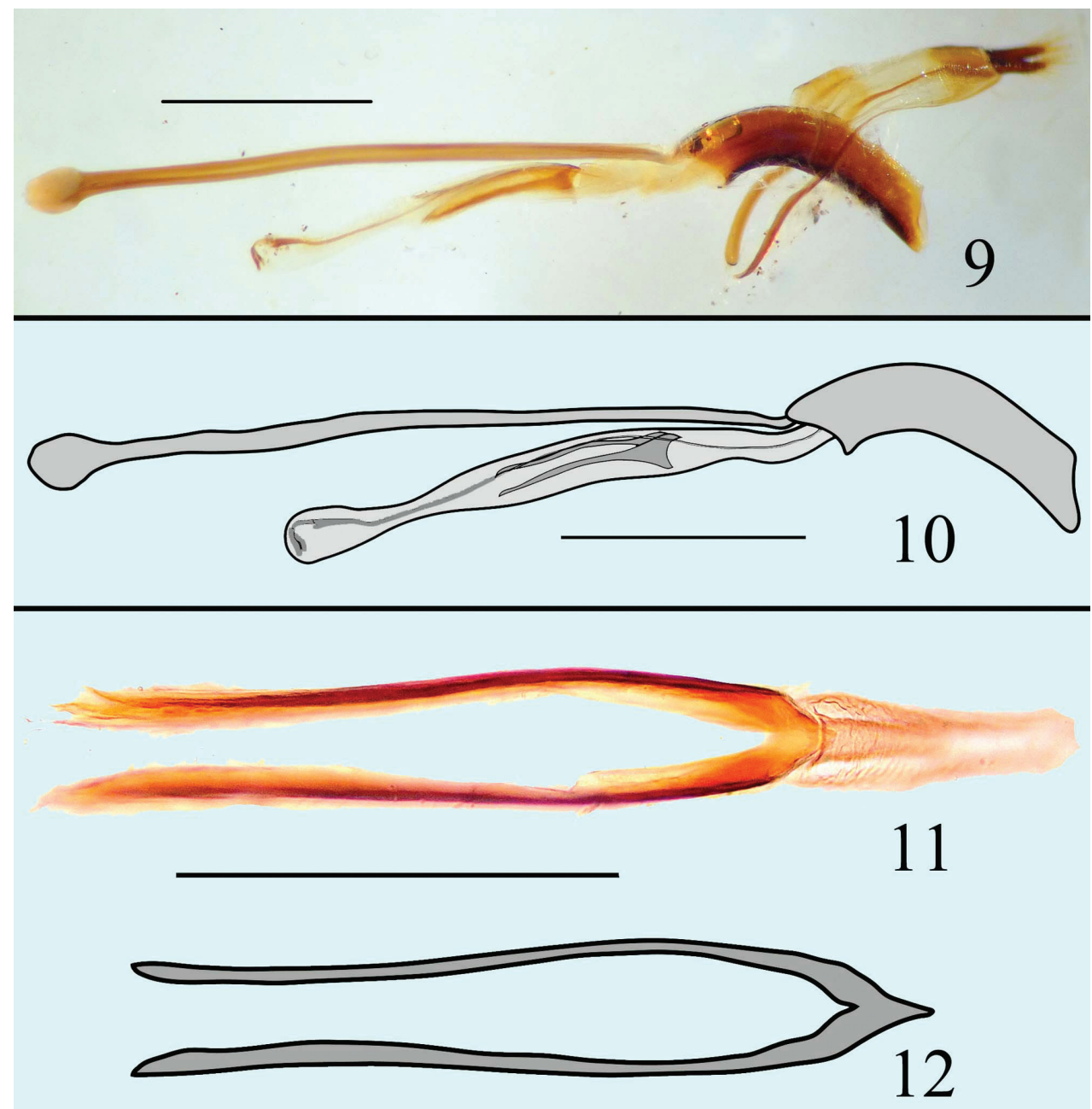

Figures 9-12. Male genitalia of Microsternus pengzhongi in lateral view 9-10 Dorsal lobe of Microsternus pengzhongi in dorsal view I I-I 2. Scale $=1 \mathrm{~mm}(\mathbf{9}, \mathbf{1 0})$, Scale $=0.5 \mathrm{~mm}(\mathbf{1 1}, \mathbf{1 2})$.

anterior margin; stridulatory files not evident. Eyes coarsely facetted. Antennomere III about 1.2 times as long as IV; antennomere VIII slightly wider than VII, about 1.3 times as wide as long; antennomere IX trapezoidal; antennomere X transverse; antennomere XI almost elliptic. Gular area with pit posterior to the postmandibular lobes. Maxillary and labial terminal palpomeres acuminate, sensory area restricted to apex. Mentum broad with anterior projection, almost triangular, slightly more than 2.3 times wider than long.

Pronotum arched, widest at base $(\mathrm{pl} / \mathrm{pw}=0.65)$; narrowed from base to apex, with formed thinned lines in lateral view; disk finely and spare punctured, except the impunctate medio-basal area, which is limited by an arched transverse row of fine punctures.

Prosternum with median area including its process elevated in an elongate triangular plane, which is distinctly bordered by a ridge on both sides and shortly rounded-subtrun- 
cate in front, bearing a few fine punctures; sides rugose, coarsely and densely punctured. Mesosternum almost conceled by prosternal process, impunctate as the mesepisterna, which is somewhat concave. Metasternum rather sparsely and strongly punctured on lateral areas, some finer punctures on median area, with a pair of mesocoxal lines strongly divergent posteriorly. Abdomen rather strongly and closely punctured, but median areas of four basal visible sternites and medio-basal area of last visible sternite with few punctures respectively; without metacoxal lines on basal visible sternite. Legs rather robust.

Scutellum pentagonal, finely and sparely punctured.

Elytra convex, with eight striae of distinct punctures on each elytron and each interstice with a row of extremely fine punctures.

Male genitalia (Figs 9-10) with flagellum bearing a straight mass on apical; flagellar apex acute with a well-separated ventral process; dorsal lobe of internal sac with long and tweezer-like structure in dorsal view (Figs 11-12).

Distribution. China (Hainan Province).

Diagnosis. Characterized by its shining body, spare punctured pronotum and dorsal lobe's unique structure of internal sac.

Etymology. This species is named in honor of Mr. Zhong Peng, one of the collectors of this new species.

\section{Microsternus perforatus Lewis, 1883}

http://species-id.net/wiki/Microsternus_perforatus

Figs 13-14, 15-21, 42, 47, 52, 63-64, 74-75, 78

Material examined. CHINA: Hainan Prov.: $4 \hat{\jmath} \widehat{\jmath}, 3+q$, Shuiman County, Mt. Wuzhishan, $18^{\circ} 54^{\prime} \mathrm{N}, 109^{\circ} 41^{\prime} \mathrm{E}$, alt. 500-800 m, 24.IV.2011, Bi Wenxuan leg. (CBWX); Zhejiang Prov.: $1 \jmath^{\lambda}, 2$, $ᄋ+$, Linan County, Mt. Tianmushan, $18^{\circ} 54^{\prime} \mathrm{N}, 109^{\circ} 41^{\prime} \mathrm{E}$, alt. 300 m, 27.IV.2008, He \& Tang leg. (SNUC)

Description. Body (Figs 13-14, 74-75, 78) elongate, length: 4.9-7.0 mm; width: 2.2-3.0 mm. Body black to blackish-brown. Each elytron with two narrow orange bands.

Head width between eyes $=7$ times eye diameter in dorsal view; punctation coarse, close, separated by half to two puncture diameters; epistome truncate, lacking marginal line on anterior margin; stridulatory files not evident. Eyes coarsely facetted. Antennomere III about 1.4 times as long as IV; antennomere VIII slightly wider than VII, about 1.2 times as wide as long; antennomere IX trapezoidal; antennomere X transverse; antennomere XI almost elliptic. Gular area with pit posterior to the postmandibular lobes (Fig. 42). Maxillary and labial terminal palpomeres acuminate, sensory area restricted to apex. Mentum broad with anterior projection, almost triangular, slightly more than 3.7 times wider than long.

Pronotum (Fig. 47) arched, widest at base ( $\mathrm{pl} / \mathrm{pw}=0.63)$; narrowed from base to apex, with formed thinned lines in lateral view (Fig. 52); disk coarsely and close punctured, except the impunctate medio-basal area, which is limited by an arched transverse row of coarse punctures. 

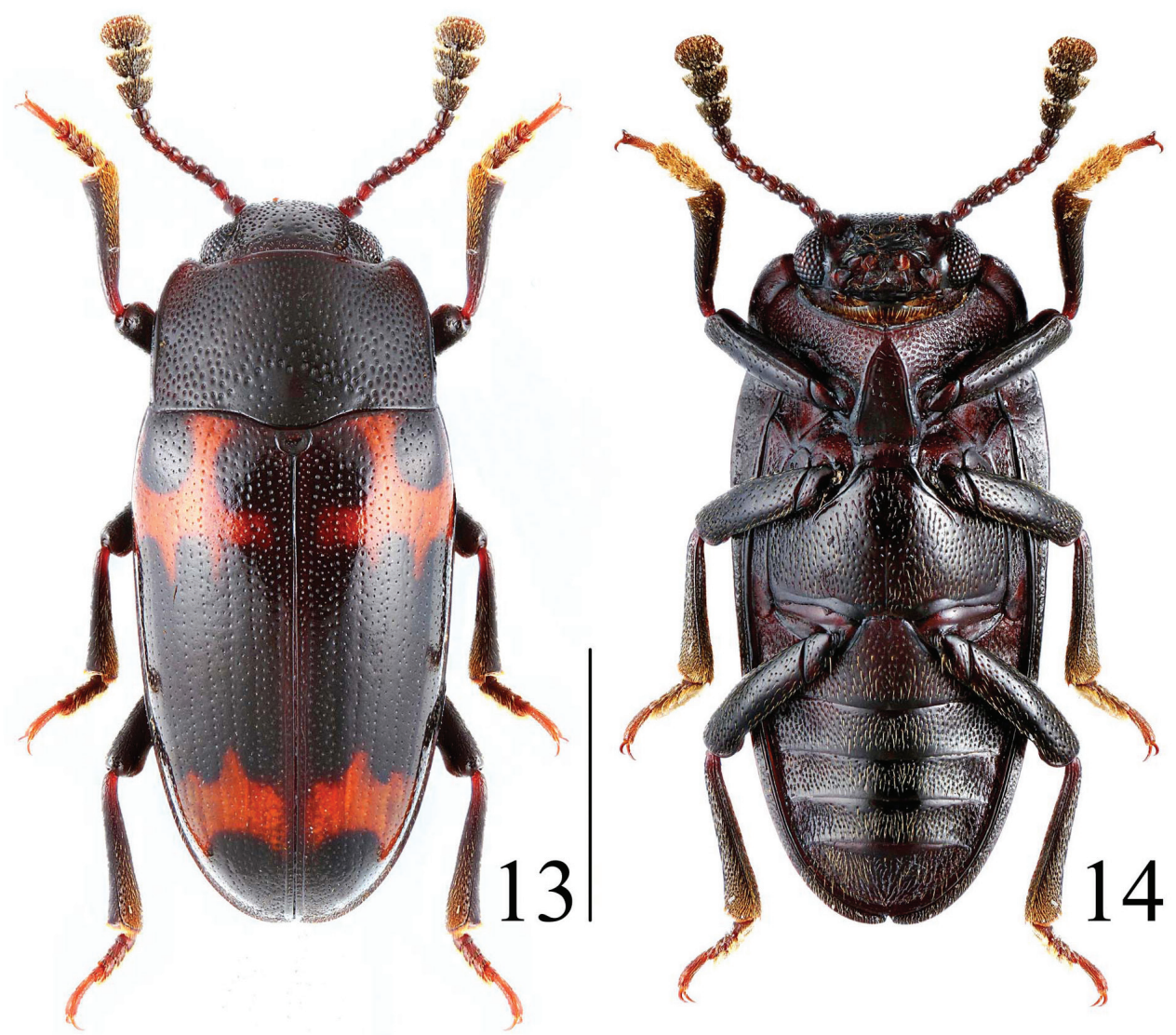

Figures 13-14. Habitus of Microsternus perforatus in dorsal and ventral view. Scale $=2 \mathrm{~mm}$.

Prosternum with median area including its process elevated in an elongate triangular plane, which is distinctly bordered by a ridge on both sides and shortly rounded-subtruncate in front, bearing a few fine punctures; sides rugose, coarsely and densely punctured. Mesosternum almost conceled by prosternal process, impunctate as the mesepisterna, which is somewhat concave. Metasternum rather sparsely and strongly punctured on lateral areas, some finer punctures on median area, with a pair of mesocoxal lines strongly divergent posteriorly. Abdomen rather strongly and closely punctured, but median areas of four basal visible sternites and medio-basal area of last visible sternite with few punctures respectively; without metacoxal lines on basal visible sternite. Legs rather robust.

Scutellum pentagonal, with each corner rounded, flattish and almost impunctate on surface.

Elytra convex, with eight striae of distinct punctures on each elytron and each interstice with a row of extremely fine punctures.

Male genitalia (Fig. 15-17) with flagellum bearing a straight mass on apical quarter; flagellar (Fig. 63-64) apex acute with a well-separated ventral process; dorsal lobe of internal sac with subhexagon edge and propeller-like hollow in dorsal view (Figs 18-19). 


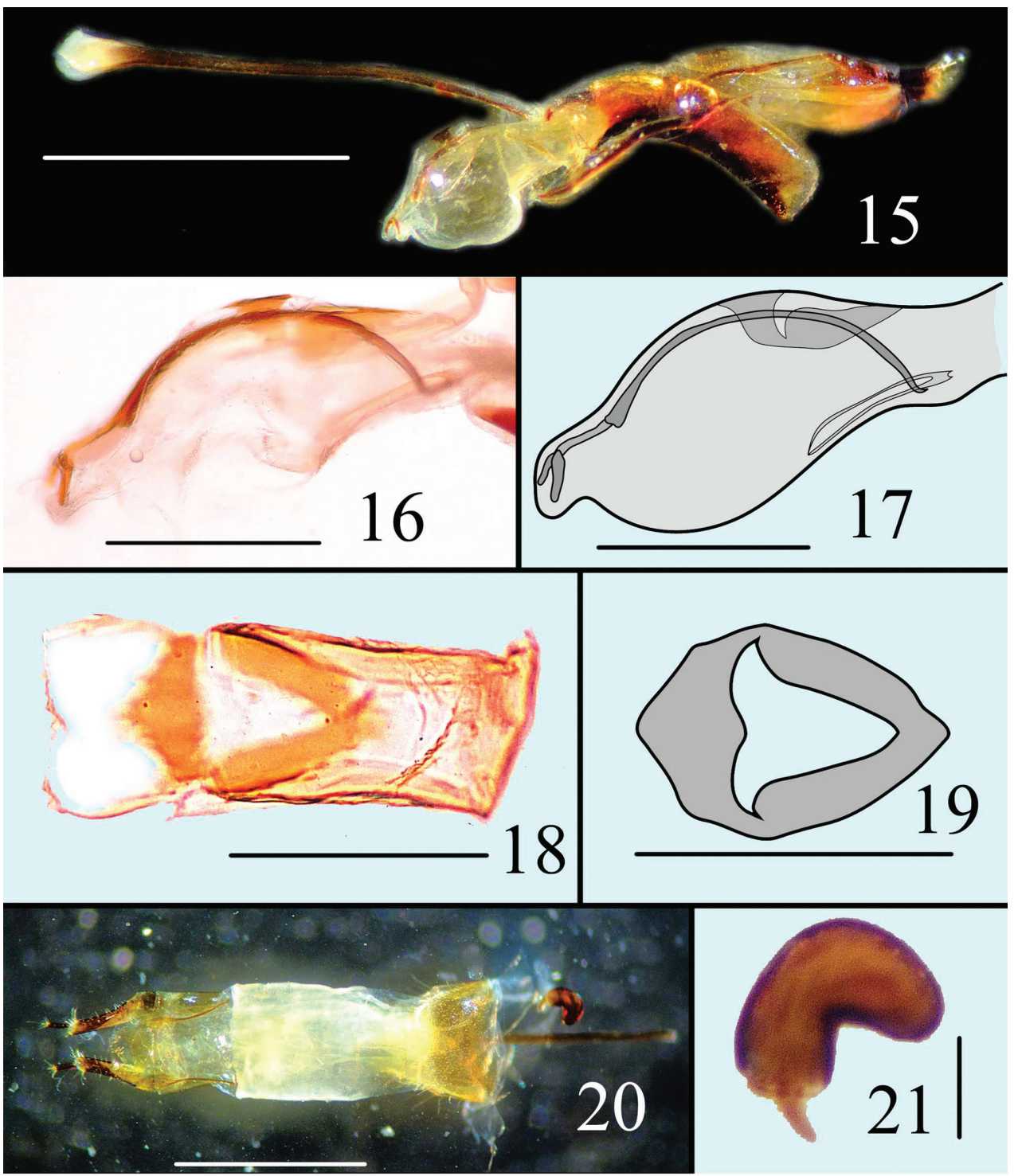

Figures I5-2I. Male genitalia of Microsternus perforatus in lateral view I5 Internal sac of Microsternus perforatus in lateral view 16-17 Dorsal lobe of Microsternus perforatus in dorsal view 18-19 Female genitalia of Microsternus perforatus in dorsal view 20 Female spermatheca of Microsternus perforatus $\mathbf{2} \mathbf{1}$. Scale $=1 \mathrm{~mm}(\mathbf{1 5}, \mathbf{2 0})$, Scale $=0.3 \mathrm{~mm}(\mathbf{1 6}, \mathbf{1 7})$, Scale $=0.2 \mathrm{~mm}(\mathbf{1 8}, \mathbf{1 9})$, Scale= $0.1 \mathrm{~mm}(\mathbf{2 1})$.

Female genitalia (Fig. 20) and spermatheca (Fig. 21) simple.

Distribution. China, Japan.

Diagnosis. Characterized by its close punctured pronotum, orange bands of elytra and dorsal lobe's unique structure of internal sac. 


\section{Microsternus tricolor Lewis, 1887}

http://species-id.net/wiki/Microsternus_tricolor

Figs 22-23, 24-29, 30-33, 41, 46, 51, 61-62, 73, 77

Microsternus tricolor taiwanicus Nakane, 1966, syn. n.

Material examined. CHINA: Hainan Prov.: $1 \hat{\jmath} \widehat{\partial}, 1 q$, Shangsi County, Mt. Wuzhishan, $18^{\circ} 54^{\prime} \mathrm{N}, 109^{\circ} 41^{\prime} \mathrm{E}$, alt. 800-1000 m, 22.IV.2011, Bi Wenxuan leg. (CBWX); $10^{\lambda}$, Jianfenglin N R. Mingfenggu Valley, $18^{\circ} 44^{\prime} \mathrm{N}, 108^{\circ} 50^{\prime} \mathrm{E}$, alt. $1000 \mathrm{~m}$, 22. V.2011, Bi Wenxuan leg. (CBWX)

Description. Body (Figs 22-23, 73, 77) elongate, length: 3.0-5.0 mm; width: 1.4-2.4 mm. Body red to reddish-brown. Each elytron orange and black spots or bands.

Head width between eyes $=8$ times eye diameter in dorsal view; punctation coarse, close, separated by half to two puncture diameters; epistome truncate, lacking marginal line on anterior margin; stridulatory files not evident. Eyes coarsely facetted. Antennomere III about 1.7 times as long as IV; antennomere VIII slightly wider than VII, about 1.2 times as wide as long; antennomere IX trapezoidal; antennomere X transverse; antennomere XI almost elliptic. Gular area with pit posterior to the postmandibular lobes (Fig. 41). Maxillary and labial terminal palpomeres acuminate, sensory area restricted to apex. Mentum broad with anterior projection, almost triangular, slightly more than 4.0 times wider than long.
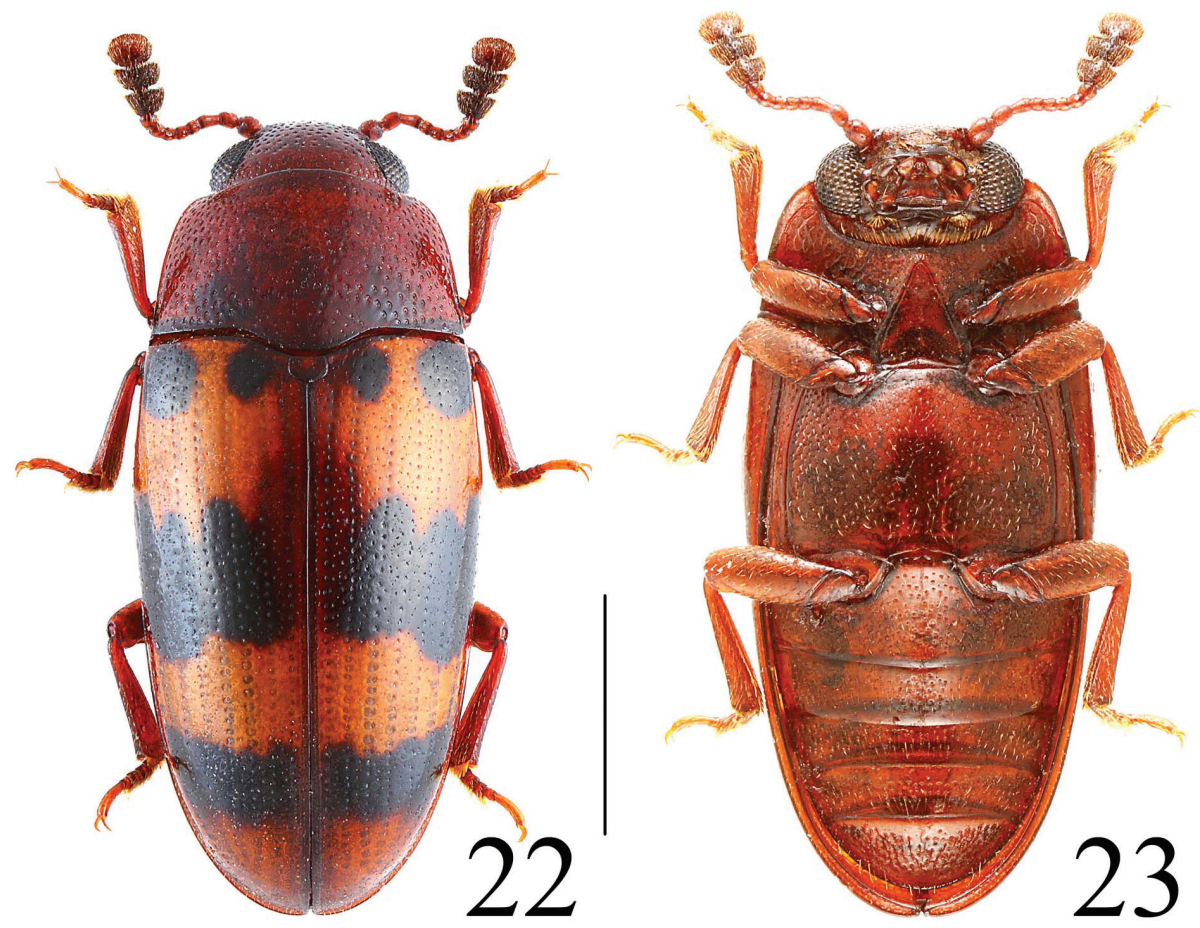

Figures 22-23. Habitus of Microsternus tricolor in dorsal and ventral view. Scale $=1 \mathrm{~mm}$. 

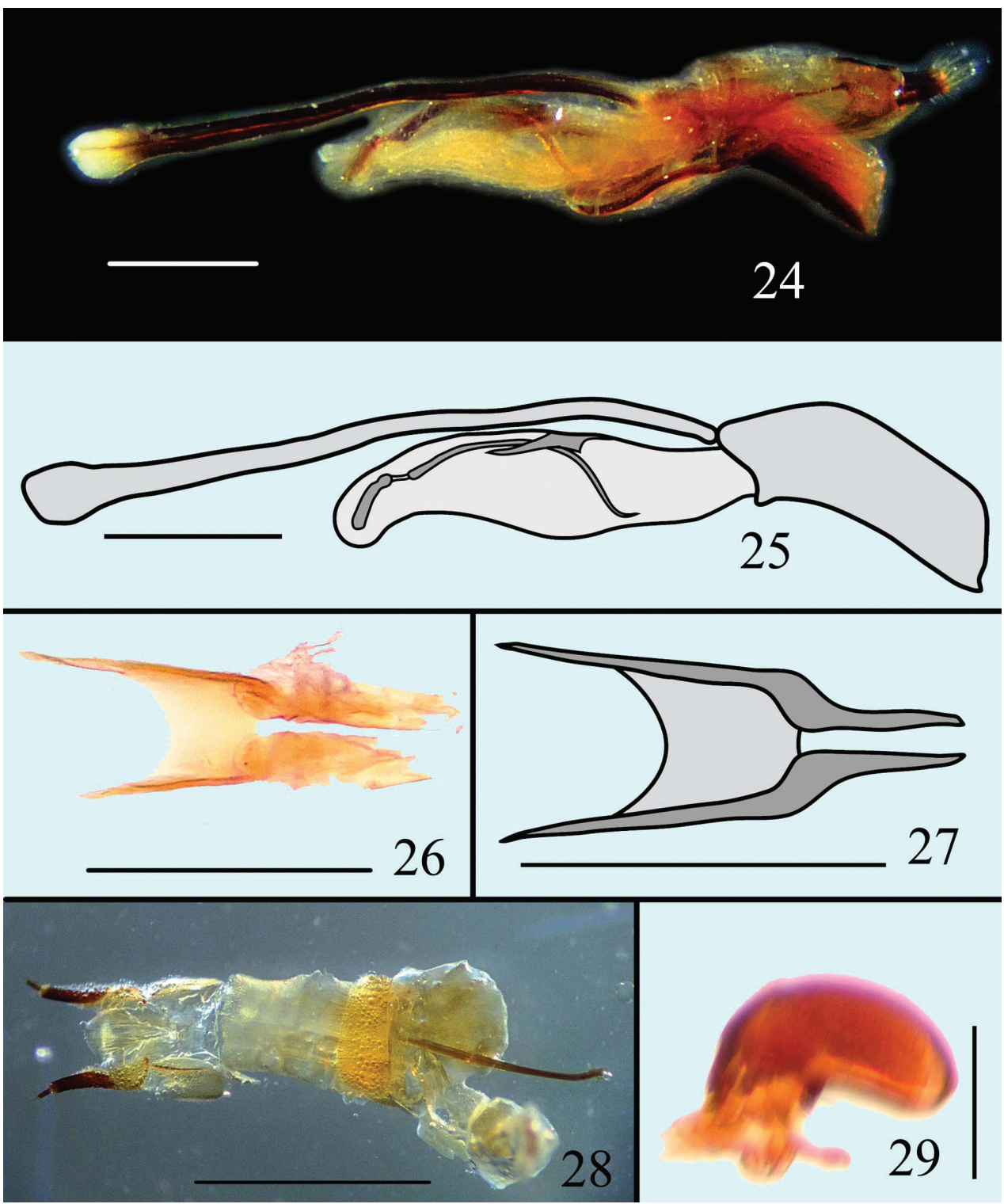

Figures 24-29. Male genitalia of Microsternus tricolor in lateral view 24-25 Dorsal lobe of Microsternus tricolor in dorsal view 26-27 Female genitalia of Microsternus tricolor in dorsal view $28 \mathrm{Fe}-$ male spermatheca of Microsternus tricolor 29. Scale $=1 \mathrm{~mm}(\mathbf{2 8})$, Scale $=0.3 \mathrm{~mm}(\mathbf{2 4}, \mathbf{2 5})$, Scale $=0.2 \mathrm{~mm}$ (26, 27), Scale=0.1 mm (29).

Pronotum (Fig. 46) arched, widest at base (pl/pw =0.58); narrowed from base to apex, with formed thinned lines in lateral view (Fig. 51); disk coarsely and close punctured, except the impunctate medio-basal area, which is limited by an arched transverse row of coarse punctures. 

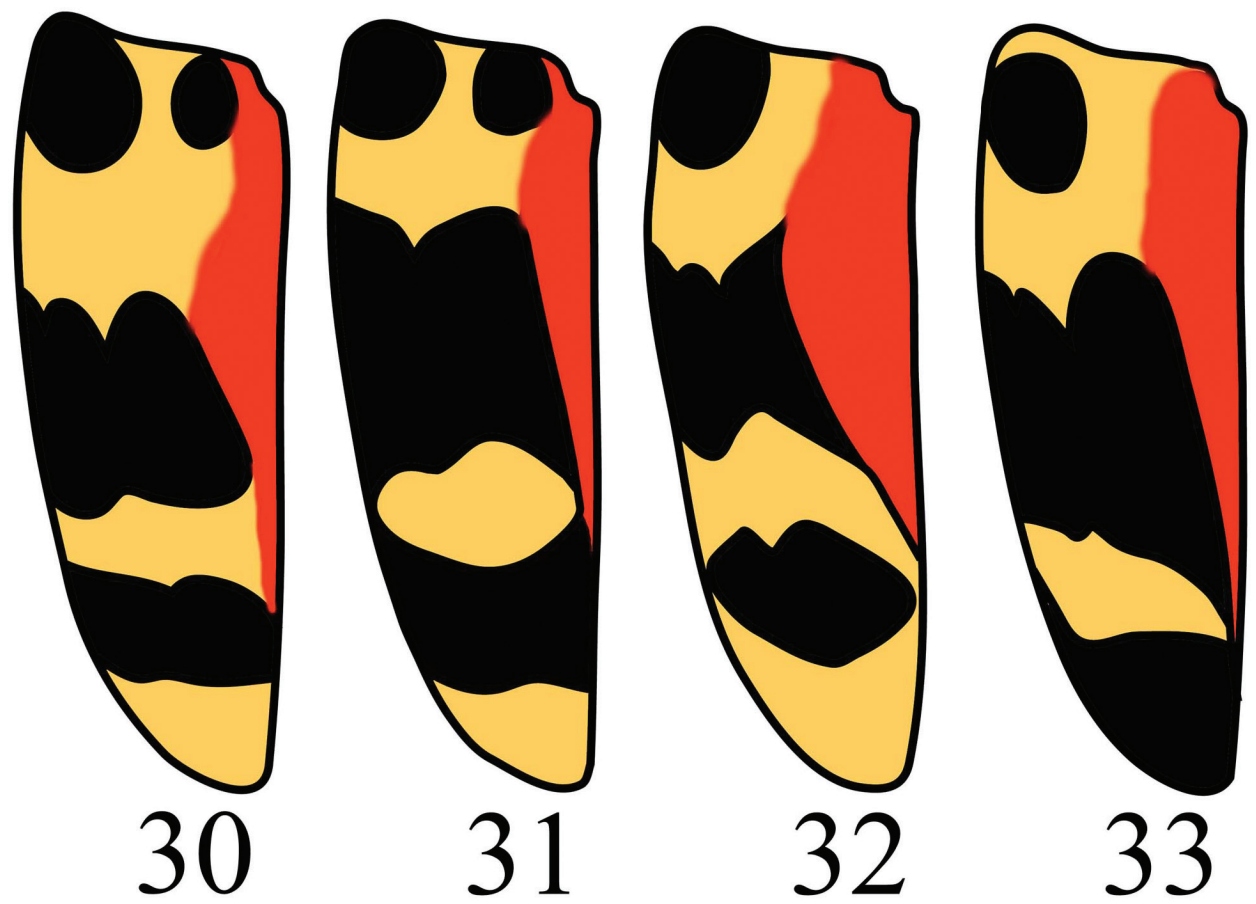

Figures 30-33. Elytra of Microsternus tricolor in dorsal view.

Prosternum with median area including its process elevated in an elongate triangular plane, which is distinctly bordered by a ridge on both sides and shortly roundedsubtruncate in front, bearing a few fine punctures; sides rugose, coarsely and densely punctured. Mesosternum almost conceled by prosternal process, impunctate as the mesepisterna, which is somewhat concave. Metasternum rather sparsely and strongly punctured on lateral areas, some finer punctures on median area, with a pair of mesocoxal lines strongly divergent posteriorly. Abdomen rather strongly and closely punctured, but median areas of four basal visible sternites and medio-basal area of last visible sternite with few punctures respectively; without metacoxal lines on basal visible sternite. Legs rather robust.

Scutellum pentagonal, with each corner rounded, flattish and almost impunctate on surface.

Elytra convex, with eight striae of distinct punctures on each elytron and each interstice with a row of extremely fine punctures.

Male genitalia (Figs 24-25) with flagellum bearing a straight mass on apical quarter; flagellar (Figs 61-62) apex acute with a well-separated ventral process; dorsal lobe of internal sac with spade -like structure in dorsal view (Figs 26-27).

Female genitalia (Fig. 28) and spermatheca (Fig. 29) simple.

Distribution. China, Japan, Russia (Far East), Oriental region. 
Diagnosis. Microsternus tricolor is characterized by its close punctured pronotum, orange and black interphased bands of elytra (Figs 30-33) and dorsal lobe's unique structure of internal sac.

Comment. Nakane described 'taiwanicus' for a single female specimen, according his description, Microsternus tricolor taiwanicus can be distinguished from Microsternus tricolor by a difference in the elytral bands: Microsternus tricolor taiwanicus has the median black patch on each side is nearly quadrate, not triangular and more extended inwards, with the inner margin more longitudinal and the front angle nearly rectangular; the posterior yellow fascia is much broader and nearly as wide as the black band before the apex. On studying the specimens of Microsternus tricolor, we find the bands of elytra are variable in different specimens (Figs 30-33), after compare the photos about Microsternus tricolor from Taiwan and Japan, we think the differences Nakane mentioned in his paper are not unique to Taiwan.

Based on the information outlined above, we considered Microsternus tricolor taiwanicus is a new synonym of Microsternus tricolor.

\section{Genus Neosternus Dai \& Zhao, gen. n.}

http://zoobank.org/1568C347-1E24-4D94-8DAB-4F603588102F

http://species-id.net/wiki/Neosternus

Figs 34-37, 38-39, 43-44, 48-49, 53-54, 55-58, 65-68, 69-72, 76

Type species. Microsternus higonius Lewis, 1887, here designated.

Description. Body small, elongate oval (Figs 34-37, 76), with legs short and robust, the tarsi cylindrical, 5-jointed, the four basal joints short, nearly equal in size and not at all dilated, the last joint long. Antennae not very long, the latter with a broad 3-jointed club. Eyes coarsely facetted. Maxillary and labial terminal palpomeres (Figs 43, 44) acuminate, sensory area restricted to apex. Pronotum (Figs 48, 49) arched, widest at base; narrowed from base to apex, with a deep sulcus along each side, which is broadly margined and the bordering gradually widened anteriorly, which formed thicken lines in lateral view (Figs 53, 54); disk coarsely and sparsely punctured, except the impunctate medio-basal area, which is limited by an arched transverse row of coarse punctures. Prosternum (Figs 38, 39) with median area including its process elevated in an elongate triangular plane, which is distinctly bordered by a ridge on both sides and shortly rounded-subtruncate in front. Mesosternum almost concealed by prosternal process. Metasternum with a pair of mesocoxal lines strongly divergent posteriorly. Abdomen without metacoxal lines on basal visible sternite. Elytra strongly convex.

Distribution. China, Japan.

Diagnosis. This new genus can be distinguished from Microsternus by body elongate oval, head without the pit posterior to the postmandibular lobes, pronotum with a deep sulcus along each side, which is broadly margined in lateral view, male genitalia with flagellum bearing a arched mass on apical quarter (Figs 55-58). Microsternus body 

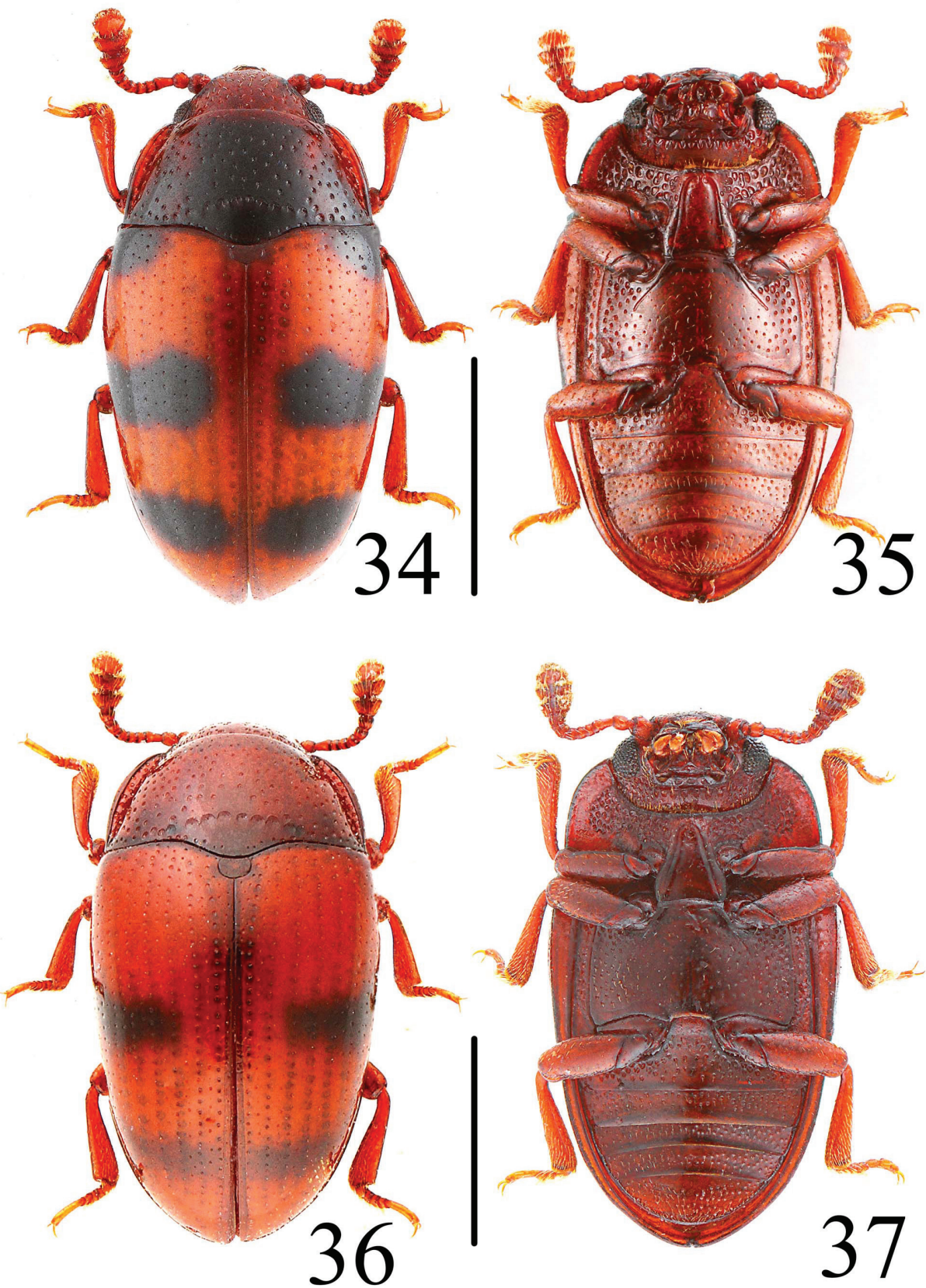

Figures 34-37. Habitus of Neosternus higonius in dorsal and ventral view 34-35 Habitus of Neosternus hisamatsui in dorsal and ventral view 36-37. Scale $=1 \mathrm{~mm}$.

elongate, head with the pit posterior to the postmandibular lobes, pronotum without a deep sulcus along each side and narrowly margined in lateral view, male genitalia with flagellum bearing a straight mass on apical quarter (Figs 59-64). 


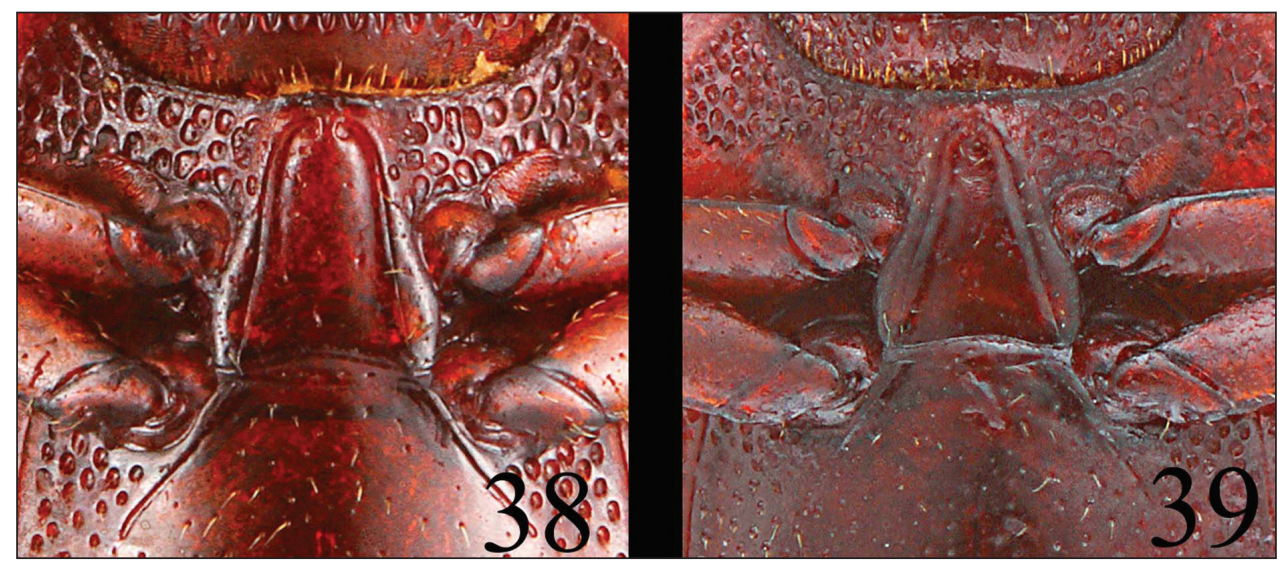

Figures 38-39. Prosternum of Neosternus higonius 38 Prosternum of Neosternus hisamatsui 39.

Etymology. As a uniquely new group within Dacnini, the generic name is derived from Microsternus, it is appropriate to call the genus "New sternus", and to abbreviate and combine the roots into a single word. The gender is masculine.

\section{Key to species of genus Neosternus}

1 Pronotum entirely reddish-brown, without markings

Neosternus hisamatsui (Nakane)

- Pronotum black or reddish-brown, with markings .................................. 2

2 Pronotum black, with a pair of red markings ...Neosternus higonius (Lewis)

- $\quad$ Pronotum reddish-brown, with a subtriangular black marking at each side of median part of anterior area and also a pair of transverse black markings at middle of base.

Neosternus taiwanus (Chûjô)

Neosternus higonius (Lewis, 1887), comb. n. http://species-id.net/wiki/Neosternus_higonius

Figs 34-35, 38, 43, 48, 53, 55-56, 65-68, 76

Microsternus higonius Lewis, 1887.

Material examined. CHINA: Fujian Prov.: $1 \hat{\jmath}$, Wuyishan City, Guadun village, $27^{\circ} 44^{\prime} \mathrm{N}, 117^{\circ} 38^{\prime} \mathrm{E}$, alt. $1200 \mathrm{~m}, 29 . V .2012$, Peng \& Dai leg. (SNUC)

Description. Body (Figs 34, 35, 76) elongate oval, length: 2.2-3.0 mm; width: 1.1-1.4 mm. Head and elytra reddish-brown; pronotum general black with reddishbrown sides; legs, palpi and base of antennae reddish-brown. Each elytron with three or four black bands. 


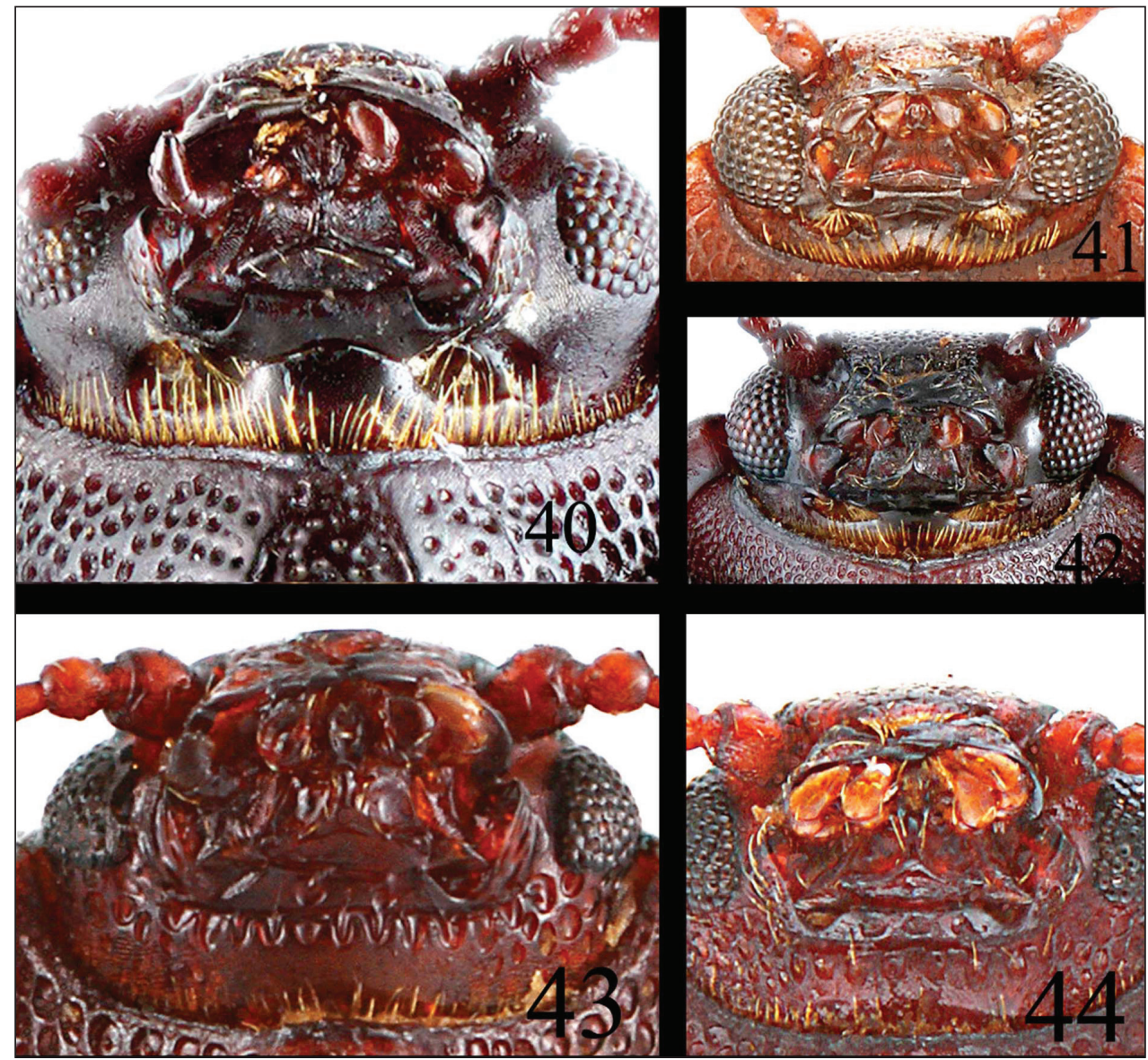

Figures 40-44. Mouth part of Microsternus ulkei $\mathbf{4 0}$ Mouth part of Microsternus tricolor 41 Mouth part of Microsternus perforatus $\mathbf{4 2}$ Mouth part of Neosternus higonius $\mathbf{4 3}$ Mouth part of Neosternus hisamatsui $\mathbf{4 4}$.

Head width between eyes $=8$ times eye diameter in dorsal view; punctation coarse, sparse, separated by 3-4 puncture diameters; epistome truncate, lacking marginal line on anterior margin; stridulatory files not evident. Eyes coarsely facetted. Antennomere III about 1.8 times as long as IV; antennomere VIII slightly wider than VII, about 1.2 times as wide as long; antennomere IX trapezoidal; antennomere $\mathrm{X}$ transverse; antennomere XI almost elliptic; relative lengths of antennomeres II-XI: 15: 18: 10: 10: 10: 10: 10: 14: 15: 17. Maxillary and labial terminal palpomeres acuminate, sensory area restricted to apex. Mentum broad with anterior projection, almost triangular, slightly more than 3.5 times wider than long.

Pronotum arched, widest at base $(\mathrm{pl} / \mathrm{pw}=0.55)$; narrowed from base to apex, with a deep sulcus along each side, which is broadly margined and the bordering gradually widened anteriorly (Fig. 48), which formed thicken lines in lateral view (Fig. 53); disk 


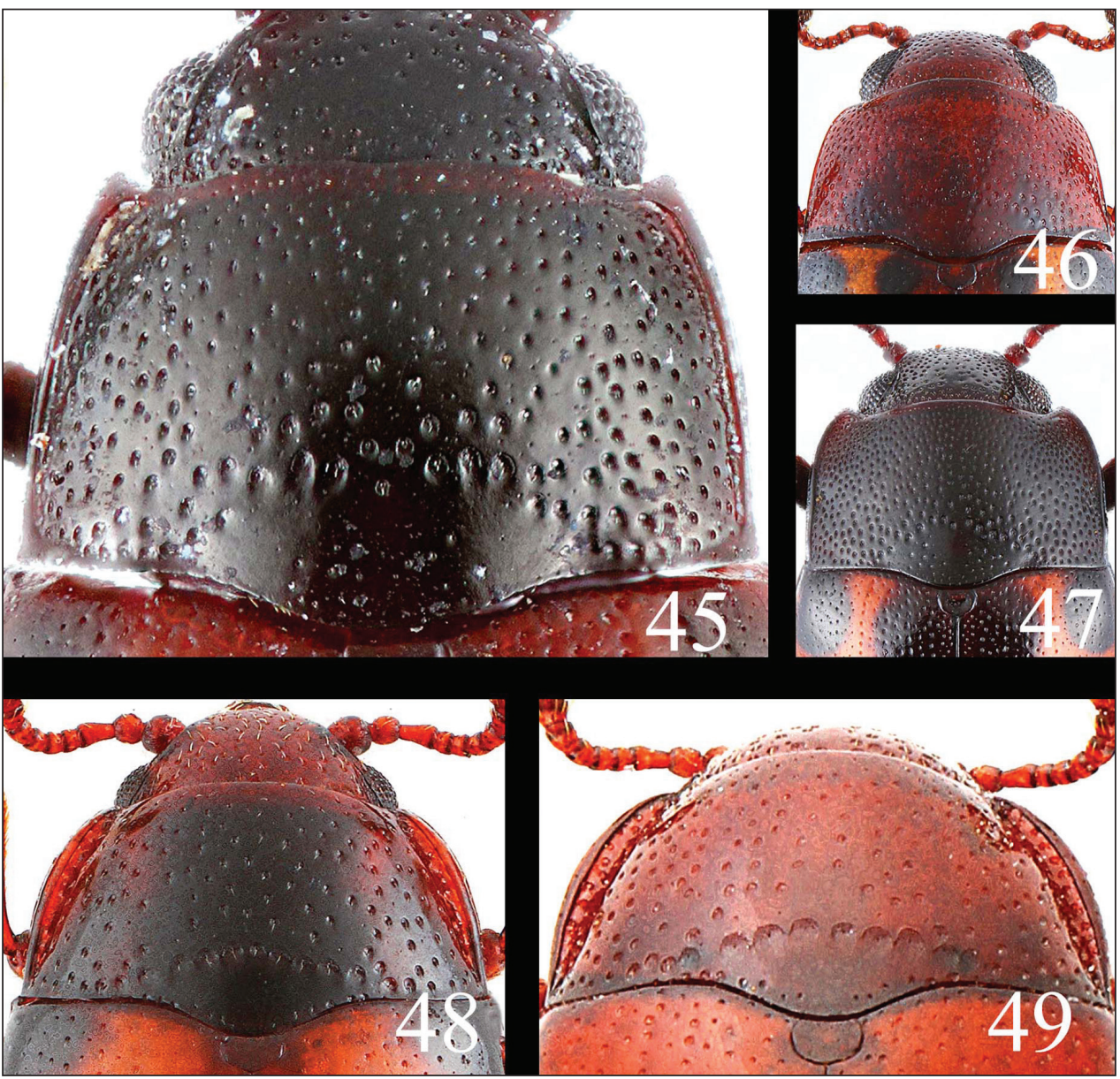

Figures 45-49. Pronotum of Microsternus ulkei in dorsal view 45 Pronotum of Microsternus tricolor in dorsal view 46 Pronotum of Microsternus perforatus in dorsal view 47 Pronotum of Neosternus higonius in dorsal view 48 Pronotum of Neosternus hisamatsui in dorsal view 49.

coarsely and sparsely punctured, except the impunctate medio-basal area, which is limited by an arched transverse row of coarse punctures.

Prosternum (Fig. 38) with median area including its process elevated in an elongate triangular plane, which is distinctly bordered by a ridge on both sides and shortly rounded-subtruncate in front, bearing a few fine punctures; sides rugose, coarsely and densely punctured. Mesosternum almost concealed by prosternal process, impunctate as the mesepisterna, which is somewhat concave. Metasternum rather sparsely and strongly punctured on lateral areas, some finer punctures on median area, with a pair of mesocoxal lines strongly divergent posteriorly. Abdomen rather strongly and closely punctured, but median areas of four basal visible sternites and medio-basal area of last visible sternite with few punctures respectively; without metacoxal lines on basal visible sternite. Legs rather robust. 


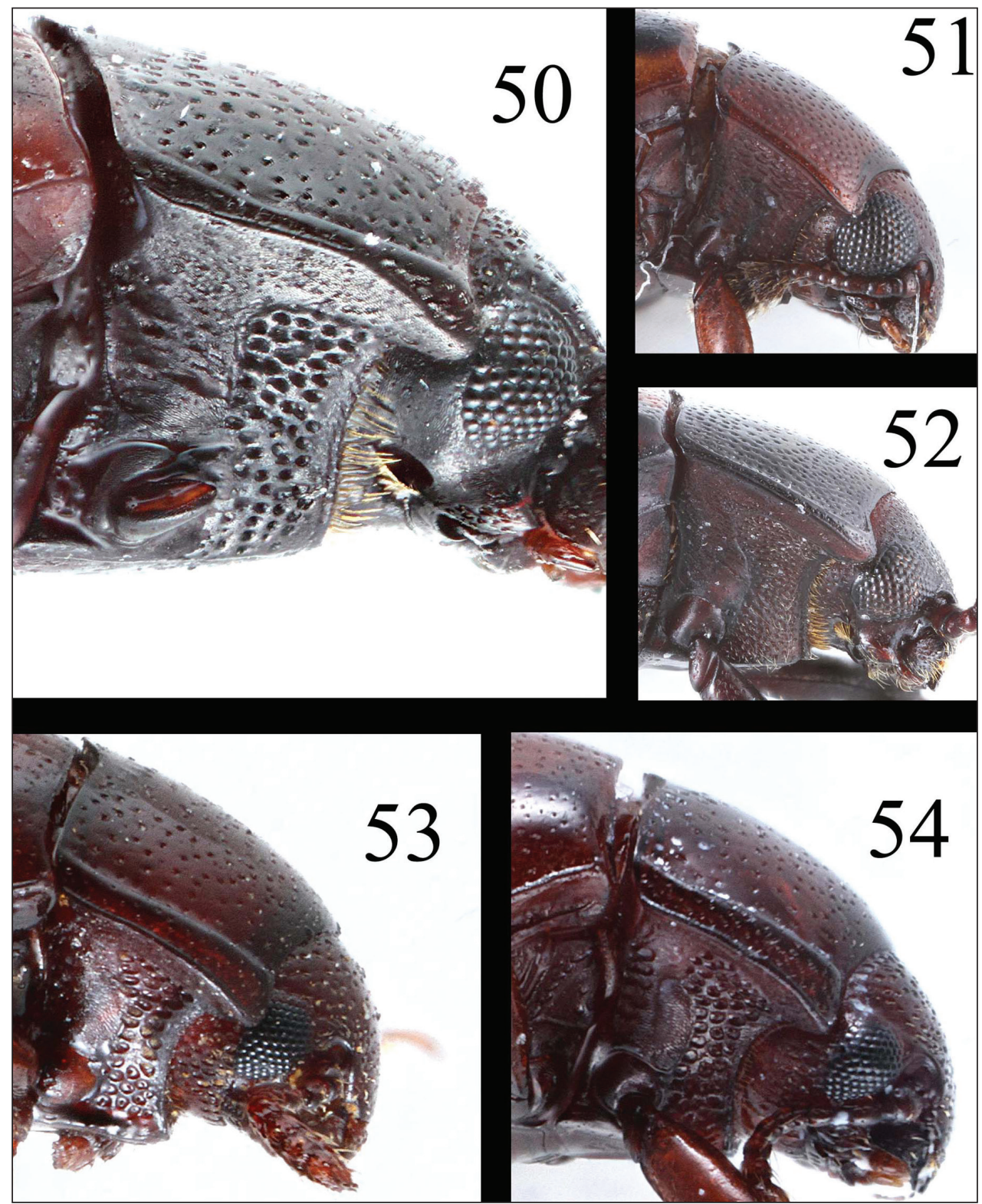

Figures 50-54. Pronotum of Microsternus ulkei in lateral view 50 Pronotum of Microsternus tricolor in lateral view $\mathbf{5}$ I Pronotum of Microsternus perforatus in lateral view $\mathbf{5 2}$ Pronotum of Neosternus higonius in lateral view 53 Pronotum of Neosternus hisamatsui in lateral view 54.

Scutellum pentagonal, with each corner rounded, flattish and almost impunctate on surface.

Elytra strongly convex, with eight striae of distinct punctures on each elytron and each interstice with a row of extremely fine punctures. 


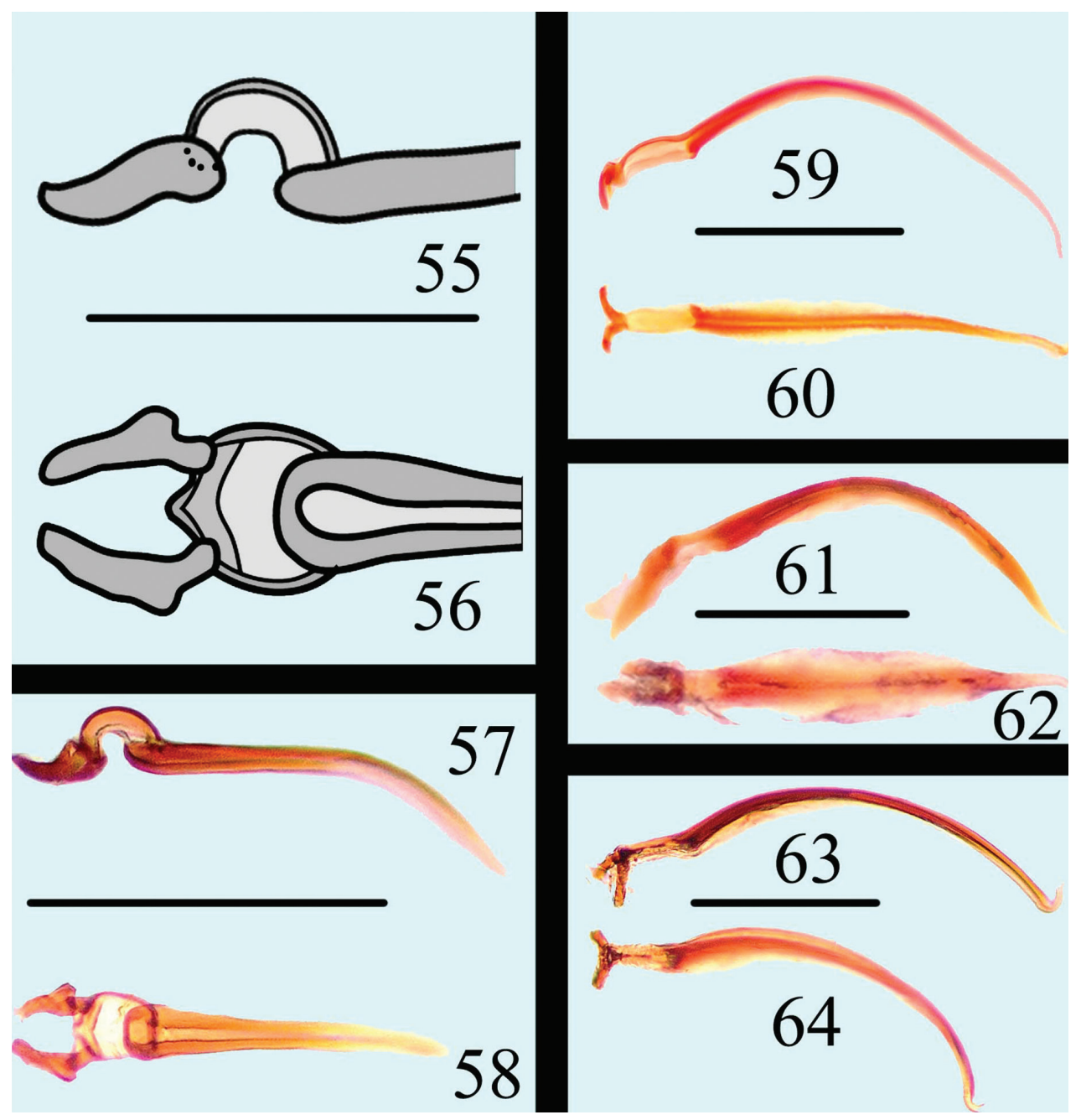

Figures 55-64. Flagellum of Neosternus higonius in lateral view 55 Flagellum of Neosternus higonius in dorsal view $\mathbf{5 6}$ Flagellum of Neosternus hisamatsui in lateral view $\mathbf{5 7}$ Flagellum of Neosternus hisamatsui in dorsal view 58 Flagellum of Microsternus ulkei in lateral view 59 Flagellum of Microsternus ulkei in dorsal view 60 Flagellum of Microsternus tricolor in lateral view 61 Flagellum of Microsternus tricolor in dorsal view 62 Flagellum of Microsternus perforatus in lateral view 63 Flagellum of Microsternus perforatus in dorsal view 64. Scale $=0.1 \mathrm{~mm}(55-56)$, Scale $=0.2 \mathrm{~mm}(57-64)$.

Male genitalia (Fig. 65) with flagellum (Fig. 66) curved, bearing a dorsal, arched, cartilaginous mass on apical quarter; flagellar apex acute with a well-separated ventral process; dorsal lobe of internal sac with separated front and triangular end (Fig. 67); ventral lobe of internal sac trident-like (Fig. 68).

Distribution. China, Japan.

Diagnosis. Characterized by its small body and black pronotum. 


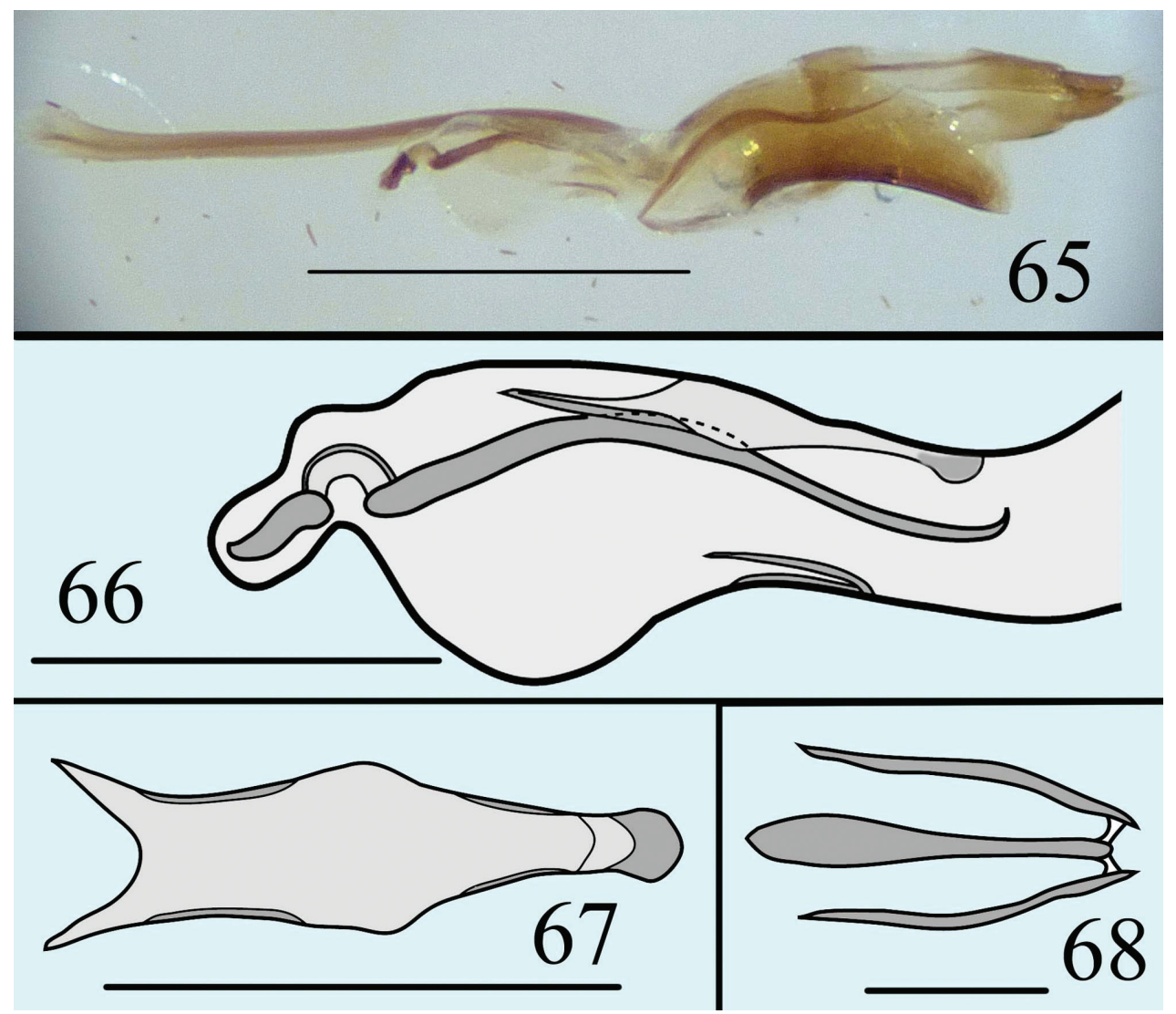

Figures 65-68. Male genitalia of Neosternus higonius in lateral view 65 Internal sac of Neosternus higonius in lateral view $\mathbf{6 6}$ Dorsal lobe of Neosternus higonius in dorsal view 6, Ventral lobe of Neosternus higonius in dorsal view 68. Scale $=0.5 \mathrm{~mm}(\mathbf{6 5})$, Scale $=0.2 \mathrm{~mm}(\mathbf{6 6}, \mathbf{6 7})$, Scale $=0.05 \mathrm{~mm}(\mathbf{6 8})$.

Neosternus hisamatsui (Nakane, 1982), comb. n. http://species-id.net/wiki/Neosternus_hisamatsui

Figs 36-37, 39, 44, 49, 54, 57-58, 69-72

Microsternus hisamatsui Nakane, 1982

Material examined. CHINA: CHINA: Guangxi Prov.: $3{ }^{\lambda}{ }^{\lambda}, 2$, $q$, Shangsi County, Mt. Shiwandashan, $21^{\circ} 54^{\prime} \mathrm{N}, 107^{\circ} 53^{\prime} \mathrm{E}$, alt. 300-500 m, 25.IV.2011, PENG, ZHAI $\&$ ZHU leg. (SNUC); $10^{\Uparrow}$, Shangsi County, Mt. Shiwandashan, $21^{\circ} 54^{\prime} \mathrm{N}, 107^{\circ} 53^{\prime} \mathrm{E}$, alt. 300-500 m, 4.V.2011, Liang Tang leg. (SNUC)

Description. Body (Figs 36, 37) elongate oval, length: 2.4-3.0 mm; width: 1.2-1.4 mm. Head and elytra reddish-brown; pronotum general reddish-brown; legs, palpi and base of antennae reddish-brown. Each elytron with two to four black bands. 

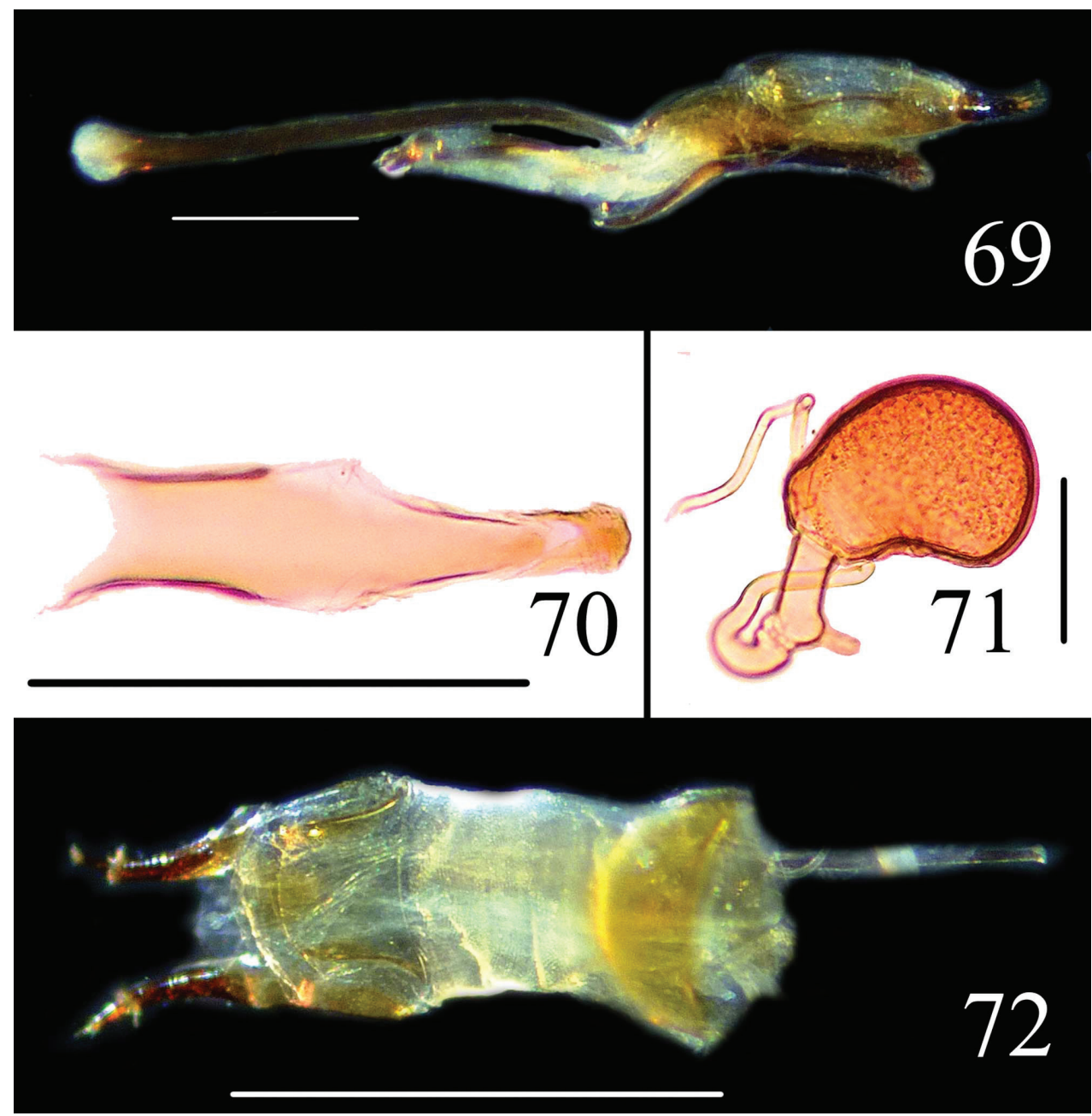

Figures 69-72. Male genitalia of Neosternus hisamatsui in lateral view 69 Dorsal lobe of Neosternus hisamatsui in dorsal view $\mathbf{7 0}$ Female genitalia of Neosternus hisamatsui in dorsal view $\mathbf{7 I}$ Female spermatheca of Neosternus hisamatsui 72. Scale $=1 \mathrm{~mm}$ (72), Scale $=0.3 \mathrm{~mm}($ 69), Scale $=0.2 \mathrm{~mm}(70)$, Scale $=0.1 \mathrm{~mm}(\mathbf{7 1})$.

Head width between eyes $=8$ times eye diameter in dorsal view; punctation coarse, sparse, separated by 3-4 puncture diameters; epistome truncate, lacking marginal line on anterior margin; stridulatory files not evident. Eyes coarsely facetted. Antennomere III about 1.8 times as long as IV; antennomere VIII slightly wider than VII, about 1.2 times as wide as long; antennomere IX trapezoidal; antennomere $\mathrm{X}$ transverse; antennomere XI almost elliptic; relative lengths of antennomeres II-XI: 15: 18: 10: 10: 10: 10: 10: 14: 15: 17. Maxillary and labial terminal palpomeres acuminate, sensory area restricted to apex. Mentum broad with anterior projection, almost triangular, slightly more than 3.5 times wider than long. 


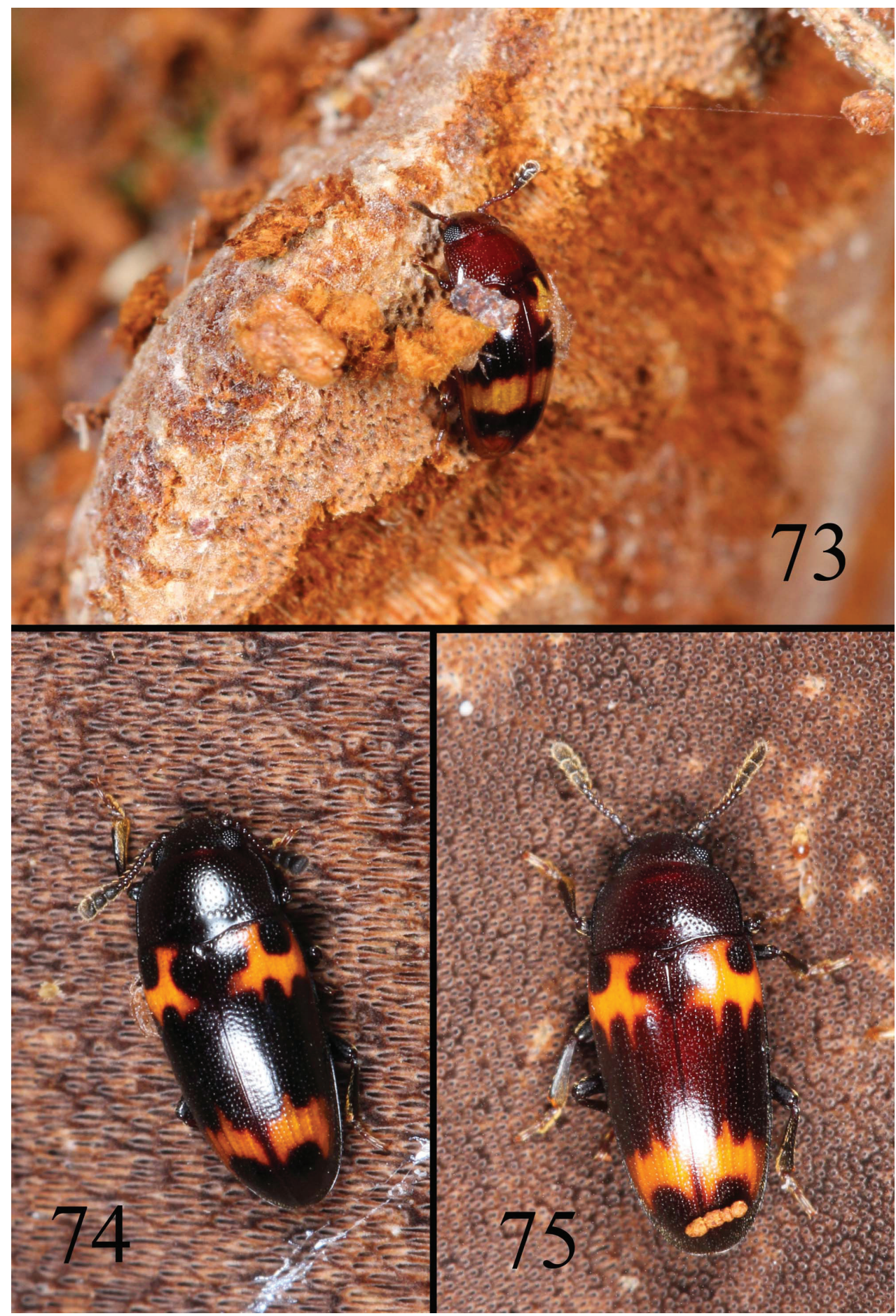

Figures 73-75. Habitat and adult feeding fungues of Microsternus tricolor $\mathbf{7 3}$ Habitat and adult feeding fungues of Microsternus perforatus 74-75. 

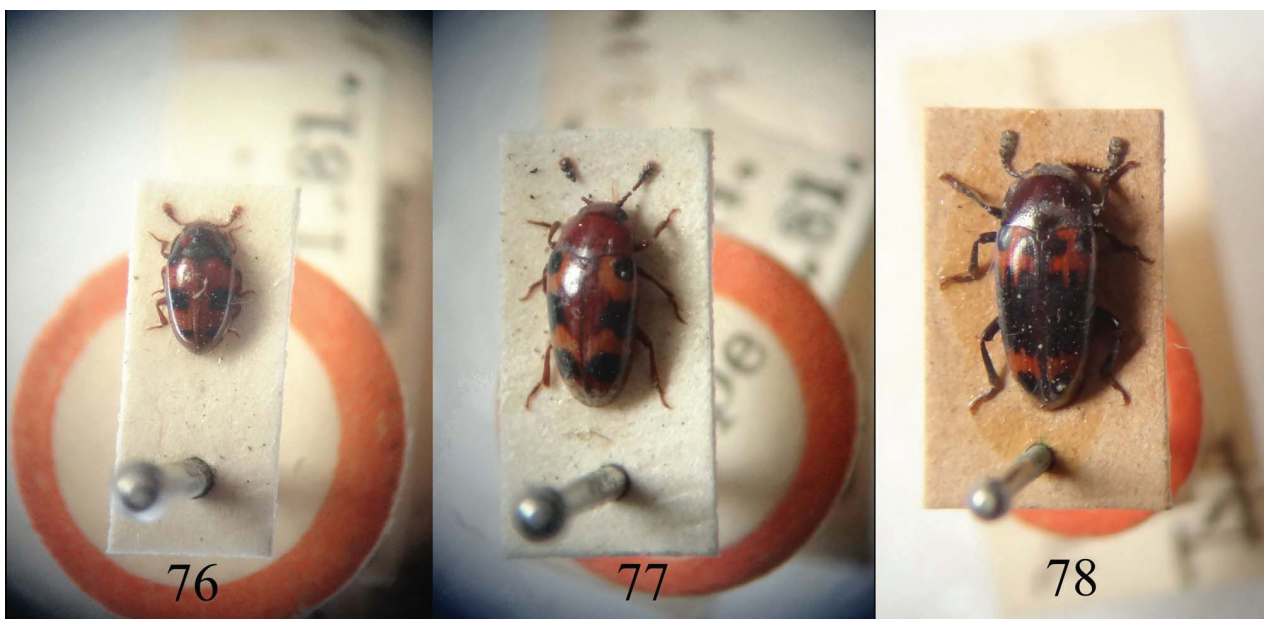

Figures 76-78. Type material of Neosternus higonius $\mathbf{7 6}$ Type material of Microsternus tricolor $\mathbf{7 7}$ Type material of Microsternus perforatus 78. (NHM).

Pronotum arched, widest at base $(\mathrm{pl} / \mathrm{pw}=0.55)$; narrowed from base to apex, with a deep sulcus along each side, which is broadly margined and the bordering gradually widened anteriorly (Fig. 49), which formed thicken lines in lateral view (Fig. 54); disk coarsely and sparsely punctured, except the impunctate medio-basal area, which is limited by an arched transverse row of coarse punctures.

Prosternum (Fig. 39) with median area including its process elevated in an elongate triangular plane, which is distinctly bordered by a ridge on both sides and shortly rounded-subtruncate in front, bearing a few fine punctures; sides rugose, coarsely and densely punctured. Mesosternum almost conceled by prosternal process, impunctate as the mesepisterna, which is somewhat concave. Metasternum rather sparsely and strongly punctured on lateral areas, some finer punctures on median area, with a pair of mesocoxal lines strongly divergent posteriorly. Abdomen rather strongly and closely punctured, but median areas of four basal visible sternites and medio-basal area of last visible sternite with few punctures respectively; without metacoxal lines on basal visible sternite. Legs rather robust.

Scutellum pentagonal, with each corner rounded, flattish and almost impunctate on surface.

Elytra strongly convex, with eight striae of distinct punctures on each elytron and each interstice with a row of extremely fine punctures.

Male genitalia (Fig. 69) with flagellum (Figs 57-58) curved, bearing a dorsal, arched, cartilaginous mass on apical quarter; flagellar apex acute with a well-separated ventral process; dorsal lobe (Fig. 70) of internal sac with separated front and triangular end; ventral lobe of internal sac trident-like.

Female genitalia (Fig. 72) and spermatheca (Fig. 71) simple.

Distribution. China, Japan.

Diagnosis. Characterized by its small body and entirely reddish-brown pronotum. 
Comment. Neosternus hisamatsui Nakane is similar to Neosternus higonius Lewis in the form and color pattern of the body. Neosternus hisamatsui can be distinguished from $N$. higonius by the pronotum entirely reddish-brown. Neosternus higonius has pronotum black with reddish-brown sides. Though the male genitalia and dorsal lobe of internal sac of $N$. higonius is similar to $N$. hisamatsui, with only one specimen of $N$. higonius available and no Japanese specimens, we can't consider $N$. hisamatsui as a synonym of $N$. higonius. This should be considered after maor materials are available for study.

Neosternus taiwanus (Chûjô, 1976), comb. n.

http://species-id.net/wiki/Neosternus_taiwanus

Microsternus taiwanus Chûjô, 1976.

Distribution. China (Taiwan).

Diagnosis. Characterized by its small body and markings of pronotum.

Comment. Chûjô described Microsternus taiwanus from Taiwan. According Chûjô's description, Neosternus taiwanus is very similar to Neosternus higonius. The only difference between these two species were the bands of pronotum and elytra as noted in the key to species. No specimens are available for study.

\section{Acknowledgements}

We thank Paul E. Skelley, Florida State Collection of Arthropods, USA for specimen loans and helpful discussions on distinction and relationship between Microsternus and Neosternus. We thank Richard A.B. Leschen, New Zealand for assistance with methods and information for this study. We thank Wen-xuan Bi for providing specimens and ecological photo for this work. We thank Zhong Peng for collecting erotylid specimens from China. We thank Yi-kai Zhang for taking type material photos from NHM. We thank Shi-bi Gao for providing photos about Microsternus specimens from Taiwan. We thank my teachers and all the collectors mentioned in the paper. The research was supported by the National Natural Science Foundation of China (No. 31101659 and No. 31172134), the Innovation Program of Shanghai Municipal Education Commission (No. 12YZ077) and by Shanghai Normal University (DZL125).

\section{References}

Chûjô M (1968) Erotylid beetles from Thailand, Laos and Viet-Nam. Studies on the erotylid beetles (21). Pacific Insects 10: 551-573. 
Chûjô M (1975) Ergebnisse der Bhutan-Expedition 1972 des Naturhistorischen Museums in Basel. Coleoptera: Fam. Erotylidae, Languriidae \& Helotidae. Entomologica Basiliensia 1: 279-292. Chûjô M (1976) Erotylid-beetles from Formosa (Taiwan) collected by Mr. M. Sakai, Ehime Unicersity, Japan, in 1972. Studies on the erotylid-beetles (24). Transactions of the Shikoku Entomological Society 13: 1-8.

Chûjô M (1988) A catalog of the Erotylidae (Insecta, Coleoptera) from the Old World (excl. the Ethiopian Region). Esakia 26: 139-185.

Chûjô M, Shibata T (1963) Description of a new erotylid-beetle from the Island AmamiOshima, Loochoos. Studies on the erotylid-beetles (14). Niponius 2: 1-2.

Crotch GR (1873) Check list of the Coleoptera of America, north of Mexico. Salem, 136 pp.

Crotch GR (1876) A revision of the coleopterous family Erotylidae. Cistula Entomologica 1: 377-572.

Deelder CL (1942) Revision of the Erotylidae (Coleoptera) of the Leiden Museum. Zoologische Mededeelingen 24(1-2): 49-115, 5 fig.

Gorham HS (1895) List of the Coleoptera in the collection of H. E. Andrewes Esq. from India and Burma, with descriptions of new species and notes. Families: Malacodermata - Erotylidae - Endomychidae. Annales de la Société Entomologique de Belgique 39: 293-330.

Heller KM (1918) Beitrag zur Kenntnis der Erotyliden der indo-australischen Region mit besonderer Berücksichtigung der philippinischen Arten. Archiv für Naturgeschichte 84, A (8): $1-121$.

Lawrence JF, Newton AF Jr. (1995) Families and subfamilies of Coleoptera (with selected genera, notes, references and data on family-group names). In: Pakaluk J, Slipinski SA (Eds) Biology, Phylogeny, and Classification of Coleoptera. Papers Celebrating the 80th Birthday. of Roy A. Crowson. Muzeum i Instytut Zoologii PAN, Warsaw, xii + 779-1006.

Leschen RAB (2003) Erotylidae (Insecta: Coleoptera: Cucujoidea): phylogeny and review. Fauna of New Zealand No. 47. Manaaki Whenua Press, Lincoln, NZ, 103 pp.

Leschen RA, Buckley TR (2007) Multistate characters and diet shifts: Evolution of Erotylidae (Coleoptera). Systematic Biology 56(1): 97-112. doi: 10.1080/10635150701211844

Lewis G (1883) On three new species of Japan Erotylidae, and notes of others. The Entomologist's Monthly Magazine 20: 138-140.

Lewis G (1887a) On a new genus of Erotylidae. The Entomologist's Monthly Magazine 24: $3-4$.

Lewis G (1887b) A list of fifty Erotylidae from Japan, including thirty-five new species and four new genera. The Annals and Magazine of Natural History (5) 20: 53-73. doi: $10.1080 / 00222938709460010$

Nakane T (1961) New or little-known Coleoptera from Japan and its adjacent regions, XV. Fragmenta Coleopterologica 1: 1-5.

Nakane T (1966) Notes on the Erotylidae of Formosa (Taiwan), with descriptions of few new forms (Coleoptera). Fragmenta Coleopterologica 16: 59-64.

Nakane T (1982) New or little-known Coleoptera from Japan and its adjacent regions. XXXIV. Reports of the Faculty of Science, Kagoshima University (Earth Sciences and Biology) 14 [1981]: 43-53. 
Narukawa N (2004) Description of a new species of the genus Microstemus (Coleoptera, Erotylidae) from Tokunoshima Is., Japan. Japanese Journal of Systematic Entomology 10: 277-279.

Robertson JA, McHugh JV, Whiting MF (2004) A molecular phylogenetic analysis of the pleasing fungus beetles (Coleoptera: Erotylidae): evolution of colour patterns, gregariousness and mycophagy. Systematic Entomology 29: 174-187. doi: 10.1111/j.03076970.2004.00242.x

Skelley PE (1998) Revision of the genus Ischyrus Lacordaire (1842) of North and Central America (Coleoptera: Erotylidae). Occasional Papers of the Florida State Collection of Arthropods 9: 134 pp.

Skelley PE, Leschen RAB (2007) Erotylinae (Insecta: Coleoptera: Cucujoidea: Erotylidae): taxonomy and biogeography. Fauna of New Zealand 59: 54 pp.

Wegrzynowicz P (2002) Morphology, phylogeny and classification of the family Erotylidae based on adult characters (Coleoptera: Cucujoidea). Genus 13(4): 435-504.

Wegrzynowicz P (2006) Family Erotylidae Latreille, 1802. In: Löbl I, Smetana A (Eds) Catalogue of Palaearctic Coleoptera, Vol. 4. Apollo Books, Stenstrup, 531-546. 